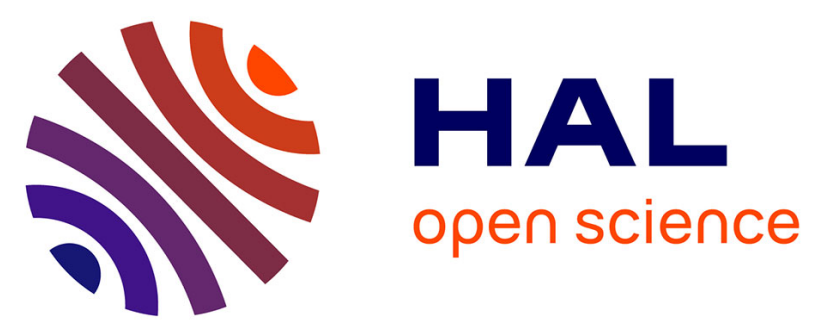

\title{
Advances in the chemistry of astatine and implications for the development of radiopharmaceuticals
}

François Guérard, Clémence Maingueneau, Lu Liu, Romain Eychenne, Jean-François Gestin, Gilles F Montavon, Nicolas Galland

\section{- To cite this version:}

François Guérard, Clémence Maingueneau, Lu Liu, Romain Eychenne, Jean-François Gestin, et al.. Advances in the chemistry of astatine and implications for the development of radiopharmaceuticals. Accounts of Chemical Research, 2021, 54 (16), pp.3264. 10.1021/acs.accounts.1c00327 . inserm03290202

\section{HAL Id: inserm-03290202 https://www.hal.inserm.fr/inserm-03290202}

Submitted on 19 Jul 2021

HAL is a multi-disciplinary open access archive for the deposit and dissemination of scientific research documents, whether they are published or not. The documents may come from teaching and research institutions in France or abroad, or from public or private research centers.
L'archive ouverte pluridisciplinaire HAL, est destinée au dépôt et à la diffusion de documents scientifiques de niveau recherche, publiés ou non, émanant des établissements d'enseignement et de recherche français ou étrangers, des laboratoires publics ou privés. 


\section{Advances in the chemistry of astatine and implications for the development of}

radiopharmaceuticals

François Guérard ${ }^{a}$, Clémence Maingueneau ${ }^{a}$, Lu Liu $^{b}$, Romain Eychenne ${ }^{a, c}$, Jean-François Gestin $^{a}$, Gilles Montavon ${ }^{b}$ and Nicolas Galland ${ }^{d} *$

${ }^{a}$ Université de Nantes, CNRS, Inserm, CRCINA, F-44000 Nantes, France

${ }^{\mathrm{b}}$ IMT-Atlantique Bretagne-Pays de la Loire - Nantes Campus, SUBATECH, UMR CNRS 6457

${ }^{c}$ Arronax GIP, Saint-Herblain, France

${ }^{\mathrm{d}}$ Université de Nantes, CNRS, CEISAM UMR 6230, F-44000 Nantes, France

Corresponding authors:

francois.guerard@univ-nantes.fr

montavon@subatech.in2p3.fr

nicolas.galland@univ-nantes.fr 


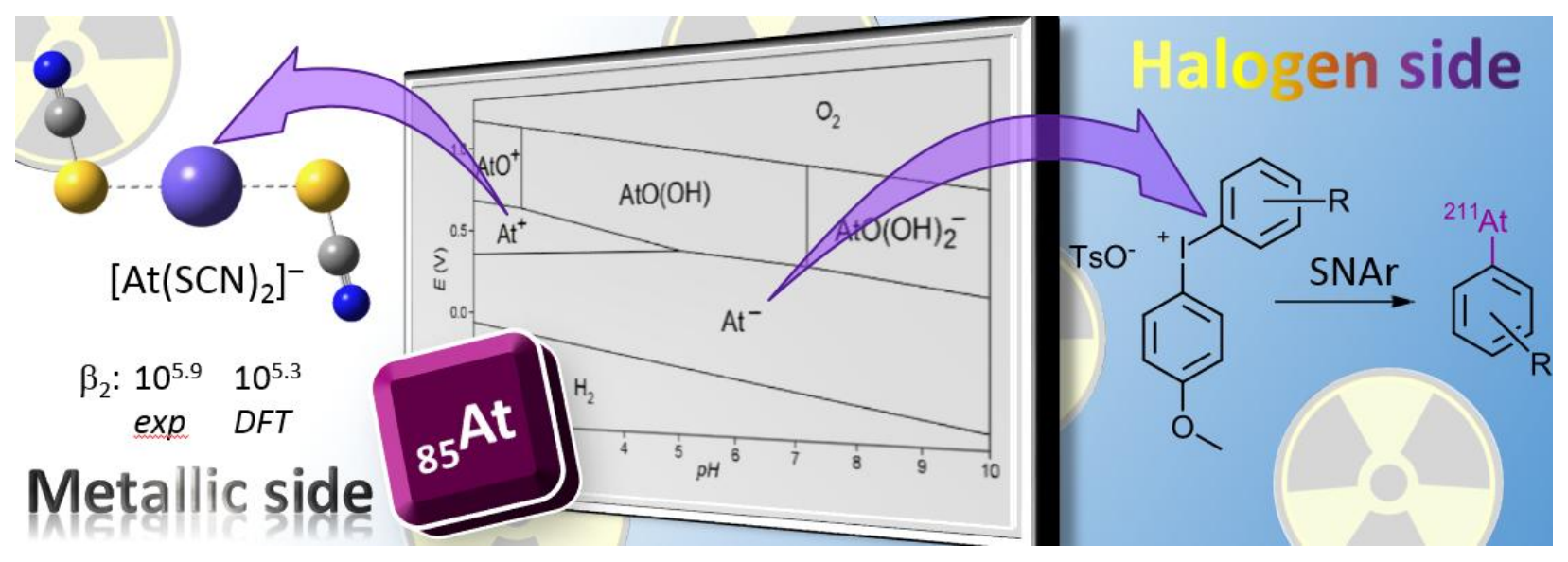

Conspectus: Astatine (At) is the rarest on Earth of all naturally-occurring elements, situated below iodine in the periodic table. While only short-lived isotopes $\left(t_{1 / 2} \leq 8.1 \mathrm{~h}\right)$ are known, ${ }^{211} \mathrm{At}$ is the object of growing attention due to its emission of high-energy alpha particles. Such radiation is highly efficient to eradicate disseminated tumors, provided that the radionuclide is attached to a cancer-targeting molecule. The interest in applications of ${ }^{211}$ At in nuclear medicine translates into the increasing number of cyclotrons able to produce it. Yet, many challenges related to the minute amounts of available astatine are to be overcome in order to characterize its physical and chemical properties. This point is of paramount importance to develop synthetic strategies and solve the labeling instability in current approaches that limits the use of ${ }^{211}$ Atlabeled radiopharmaceuticals. Despite its discovery in the 1940 s, only the last decade has seen a significant rise in the understanding of astatine's basic chemical and radiochemical properties, thanks to the development of new analytical and computational tools.

In this Account, we give a concise summary of recent advances in the determination of physicochemical properties of astatine, putting in perspective the duality of this element which exhibits 
both the characteristics of a halogen and of a metal. Striking features were evidenced in the recent determination of its Pourbaix diagram such as the identification of stable cationic species, $\mathrm{At}^{+}$and $\mathrm{AtO}^{+}$, contrasting with other halogens. Like metals, these species were shown to form complexes with anionic ligands and to exhibit a particular affinity for organic species bearing soft donor atoms. On the other hand, astatine shares many characteristics with other halogen elements. For instance, the $\mathrm{At}^{-}$species exists in water, but with the least range of $E_{\mathrm{H}}$-pH stability in the halogen series. Astatine can form molecular interactions through halogen bonding, and it was only recently identified as the strongest halogen-bond donor. This ability is nonetheless affected by relativistic effects, which translate to other peculiarities for this heavy element. For instance, the spin-orbit coupling boosts astatine's propensity to form charge-shift bonds, catching up with the behavior of the lightest halogens (fluorine, chlorine).

All these new data have an impact on the development of radiolabeling strategies to turn ${ }^{211} \mathrm{At}$ into radiopharmaceuticals. Inspired by the chemistry of iodine, the chemical approaches have sparsely evolved over the past decades and have long been limited to electrophilic halodemetallation reactions to form astatoaryl compounds. Conversely, recent developments have favored the use of the more stable $\mathrm{At}^{-}$species including the aromatic nucleophilic substitution with diaryliodonium salts, or the copper-catalyzed halodeboronation of arylboron precursors. However, it is clear that new bonding modalities are necessary to improve the in vivo stability of ${ }^{211}$ At-labeled aryl compounds. The tools and data gathered over the past decade will contribute to instigate original strategies for overcoming the challenges offered by this enigmatic element. Alternatives to the C-At bond such as the B-At and the metal-At bonds are typical examples of exciting new axes of research. 


\section{Key references}

- Guo, N.; Maurice, R.; Teze, D.; Graton, J.; Champion, J.; Montavon, G.; Galland, N. Experimental and Computational Evidence of Halogen Bonds Involving Astatine. Nat. Chem. 2018, 10, 428-434. ${ }^{1}$

This article reports the very first experimental characterization of halogen bonds mediated by astatine, quantum chemistry calculations making up for the impossibility of using spectroscopic tools.

- $\quad$ Leimbach, D.; Karls, J.; Guo, Y.; Ahmed, R.; Ballof, J.; Bengtsson, L.; Boix Pamies, F.; Borschevsky, A.; Chrysalidis, K.; Eliav, E.; Fedorov, D.; Fedosseev, V.; Forstner, O.;

Galland, N.; Garcia Ruiz, R. F.; Granados, C.; Heinke, R.; Johnston, K.; Koszorus, A.; Köster, U.; Kristiansson, M. K.; Liu, Y.; Marsh, B.; Molkanov, P.; Pašteka, L. F.; Ramos, J. P.; Renault, E.; Reponen, M.; Ringvall-Moberg, A.; Rossel, R. E.; Studer, D.; Vernon, A.; Warbinek, J.; Welander, J.; Wendt, K.; Wilkins, S.; Hanstorp, D.; Rothe, S. The Electron Affinity of Astatine. Nat. Commun. 2020, 11, 3824. ${ }^{2}$

Eighty years after the discovery of astatine, its electronic affinity is finally measured thanks to a state-of-the-art technique of laser photodetachment spectroscopy carried out at CERN.

- $\quad$ Sergentu, D.-C.; Teze, D.; Sabatié-Gogova, A.; Alliot, C.; Guo, N.; Bassal, F.; Silva, I. D.; Deniaud, D.; Maurice, R.; Champion, J.; Galland, N.; Montavon, G. Advances on the 
Determination of the Astatine Pourbaix Diagram: Predomination of $\mathrm{AtO}(\mathrm{OH})^{2-}$ over $\mathrm{At}^{-}$in $\mathrm{Basic}$ Conditions. Chem. Eur. J. 2016, 22, 2964-2971.²

A significant step towards the completion of the Pourbaix diagram is presented in this study, judiciously combining macroscopic data from radiochemical experiments and information at the molecular scale provided by DFT calculations.

- Berdal, M.; Gouard, S.; Eychenne, R.; Marionneau-Lambot, S.; Croyal, M.; FaivreChauvet, A.; Chérel, M.; Gaschet, J.; Gestin, J.-F.; Guérard, F. Investigation on the Reactivity of Nucleophilic Radiohalogens with Arylboronic Acids in Water: Access to an Efficient SingleStep Method for the Radioiodination and Astatination of Antibodies. Chem. Sci. 2021, 12, 1258$1468 .^{4}$

The robust ${ }^{211}$ At-labeling procedure reported herein facilitates the preparation of radiopharmaceuticals and the transfer to the clinic as ready-to-use kits. Being also applicable to radioiodination, it opens perspectives for radiotheranostic applications.

\section{Introduction}

Discovered in 1940 after irradiation experiments of bismuth by accelerated $\alpha$ particles, astatine $(Z=85)$ is the rarest naturally occurring element. ${ }^{5}$ All of its 32 known isotopes exhibit short half-lives (125 ns to $8.1 \mathrm{~h}$ ), justifying the Greek origin of its name, astatos, meaning unstable. The ${ }^{211}$ At isotope $\left(\mathrm{t}_{1 / 2}=7.2 \mathrm{~h}\right)$ decays to stable ${ }^{207} \mathrm{~Pb}$ through a double-branched pathway, producing high-energy $\alpha$ particles $(5.9$ and $7.5 \mathrm{MeV}$ ) of great interest for targeted radionuclide therapy of cancers. ${ }^{6} \alpha$ particles exhibit short path length $(<100 \mu \mathrm{m})$, resulting in a higher cytotoxicity for nearby malignant cells and reduced irradiation of surrounding healthy tissues in 
comparison to $\beta^{-}$particles, which is particularly appropriate for the treatment of small clusters or isolated cancer cells (Figure 1) ${ }^{7,8}$

(A)

$$
{ }^{209} \mathrm{Bi}+\alpha \longrightarrow{ }^{211} \mathrm{At}+2 \mathrm{n}
$$

(B)

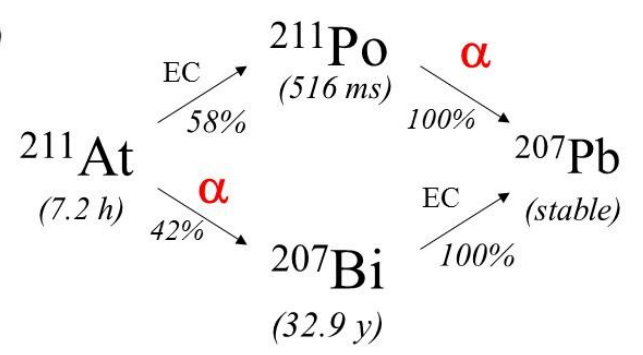

$\mathrm{EC}=$ electron capture

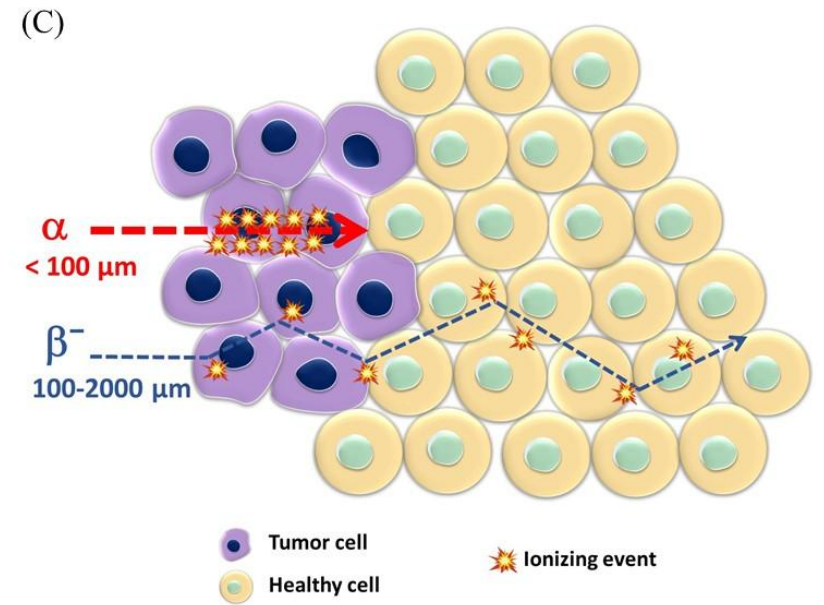

Figure 1. A) Nuclear reaction to produce ${ }^{211}$ At from bismuth. B) ${ }^{211}$ At decay scheme. C) Simplified view of $\alpha$ vs. $\beta$ particle track and related ionization density.

Among the eight main radionuclides considered for targeted alpha therapy, ${ }^{211} \mathrm{At}$, when coupled to a cancer-targeting agent, appears very promising as illustrated by the first clinical trial reported in 2008 for glioblastoma treatment ${ }^{9}$ and more recently in studies demonstrating longterm low toxicity of ovarian cancer treatment. ${ }^{10}$ To expand the number of potential carrier compounds applicable to ${ }^{211} \mathrm{At}$, the need of innovative strategies remains to be solved even 80 years after astatine discovery, in particular to improve reactions robustness and in vivo labeling stability. The design of optimal astatine-based radiopharmaceuticals has long been hampered by the elusive nature of this element. ${ }^{11}$ For instance, the measurements of atomic ionization energy and electron affinity, which are fundamental quantities for understanding the subtle mechanisms of bond formation, were only reported in $2013^{12}$ and $2020^{2}$, respectively. A number of astatine's properties remain thus far inaccessible because the radioelement is available from artificial production at the nanogram scale at best, making usual spectroscopic tools inapplicable to 
physical and chemical characterization. Although a number of astatine's characteristics are clearly similar to that of halogens, this element also behaves as a metal in some conditions, which led Visser to qualify it as a "chameleon", ${ }^{13}$ a term that perfectly reflects its multifaceted character.

With the completion in the late 2000's of the Arronax cyclotron facility, ${ }^{14}$ one of the few accelerators in the world exhibiting adequate characteristic to produce ${ }^{211} \mathrm{At},{ }^{15}$ it became obvious, once this radionuclide had become available routinely to us, that new methodologies and new tools were needed to quantitatively evaluate astatine chemistry. It is in this context that we initiated research programs which intended to better understand this element's basic chemical properties, and eventually benefit the radiolabeling chemistry. A decade later, these efforts are beginning to bear fruits as the outline of this element's chemistry has become clearer and radiolabeling reactions of higher efficiency and robustness have been identified, as illustrated in this Account.

\section{Pourbaix diagram of astatine - evidences of a metallic behavior}

In the early 2000s, astatine was suspected to exist under three different oxidation states in water. ${ }^{13,16-19}$ However, the exact species involved remained unclear and sometimes inconsistent depending on authors, e.g. $\mathrm{At}^{+}$(Figure 2). They were mostly extrapolated from iodine as is still done now. ${ }^{20}$ The existence of $\operatorname{At}(0)$ was notably unproven, which motivated our initial investigations. 


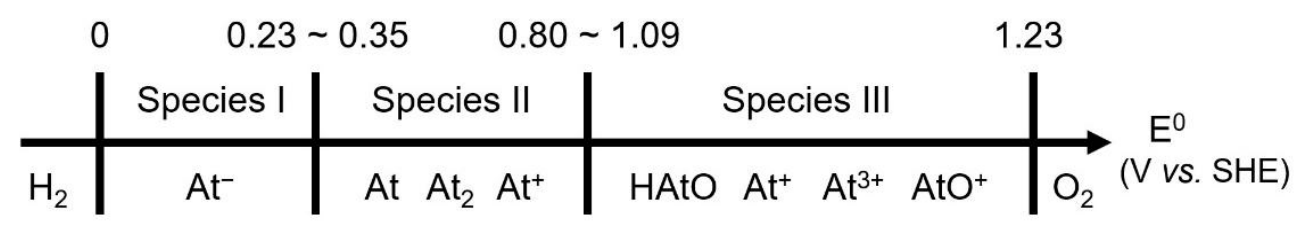

Figure 2. Proposed astatine species from the literature, at $\mathrm{pH} \sim 0$ according to redox conditions. Data from ref. 13, 16-19.

\subsection{Construction of the Pourbaix diagram}

In order to characterize At species at ultra-trace concentrations, which are unidentifiable by conventional spectroscopic tools, a dual experimental/theoretical approach was followed. In addition to electromobility and chromatographic techniques coupled with radio-detection, we adapted the Schubert's method ${ }^{21}$ to the study of species at trace level. ${ }^{22}$ The principle is based on the partitioning of total astatine between two immiscible phases, characterized by a distribution ratio $(D)$. Variation in $D$ when experimental parameters are modified $(\mathrm{pH}$, redox potential, ligand concentration, etc.) is indicative of a change in astatine speciation. The analysis of these data, on the basis of a classical equilibrium model, allows one to trace the formed species and to determine the associated thermodynamic constants. The results are then confronted with those of quantum mechanical calculations on speculated species. Since astatine is a heavy element subject to relativistic effects, specific computational approaches were implemented for its study. In particular, the spin-orbit coupling (SOC) can strongly influence astatine chemistry. ${ }^{23-28}$ With the development of two-component relativistic methods in the 2000s, notably in the framework of the density functional theory (DFT), it became possible to determine the structure and 
thermodynamic properties of medium-size compounds. As a general rule, the existence of At species is validated if experimental and theoretical data converge towards the same answer.

Our research was based on the assumption that the $\mathrm{At}^{-}$species exists, similarly to halides observed from fluorine to iodine. The first step was to confirm its existence. In non-alkaline and reducing medium, a monocharged anionic species was evidenced by ion exchange chromatography. ${ }^{29}$ Electromobility measurements strengthened our hypothesis, a negative species being confirmed. ${ }^{30}$ Molecular dynamics simulations on $\mathrm{At}^{-}$corroborated the obtained mobility value. ${ }^{31}$ Taken together, these data fully ascertain the existence of $\mathrm{At}^{-}$. The next step was to study the conversion of $\mathrm{At}^{-}$when $E_{\mathrm{H}}$ increases. One of the most-controversial species in the literature was species II, found in acidic media in mild redox conditions (Figure 2).
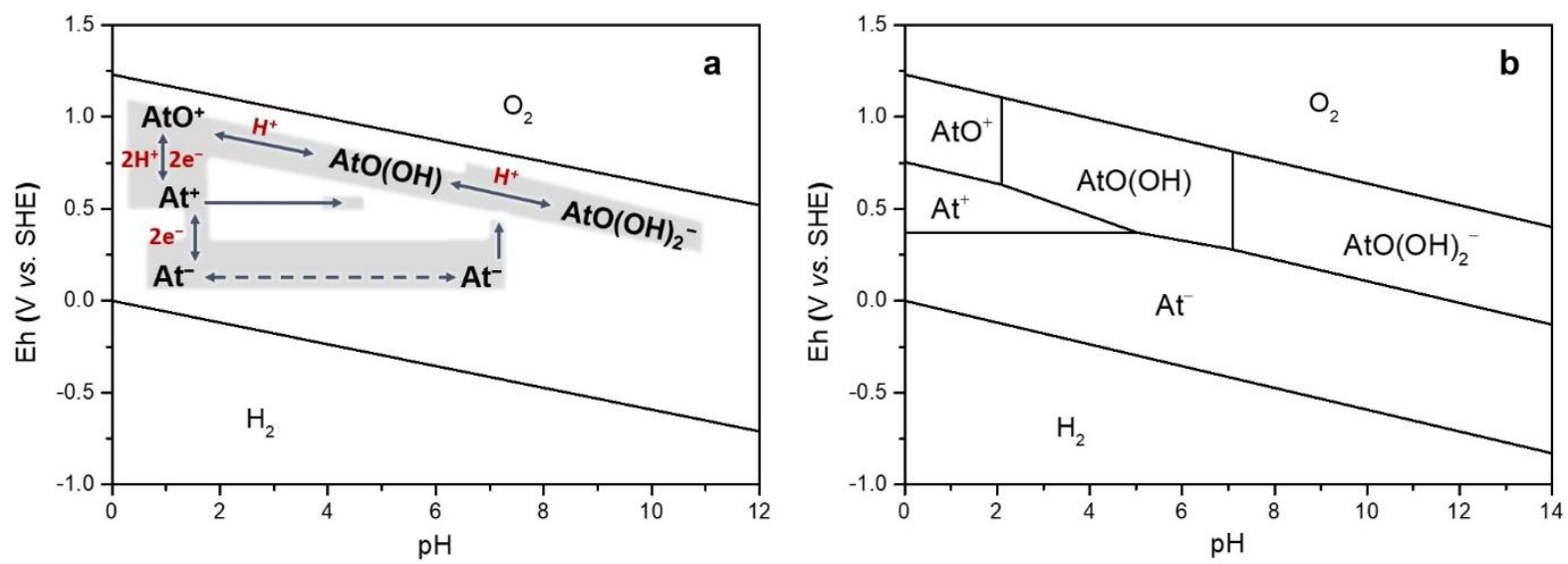

Figure 3. Pourbaix diagram in the range of water stability. a) Shadow zones correspond to the explored $E_{\mathrm{H}}-\mathrm{pH}$ ranges; b) Proposed diagram for At.

Astatine was suggested to have an oxidation number either of 0 or +1 . In acidic conditions, our experimental work revealed that the oxidation of $\mathrm{At}^{-}$to form species II involved an exchange of two electrons, independently of $\mathrm{pH}$ (Figure 3). ${ }^{32}$ Hence, the existence of an $\operatorname{At}(0)$ species would 
be possible only as $\mathrm{At}_{2}$. Such a diatomic species is highly unlikely given the extremely low astatine concentration in studied solutions. Moreover, our DFT calculations predict a standard potential of $\sim 0.17 \mathrm{~V}$ for the $\mathrm{At}_{2} / \mathrm{At}^{-}$couple, which is inconsistent with the measured value of $0.36 \pm 0.01 \mathrm{~V} .{ }^{32}$ The exchange of two electrons would therefore imply the formation of a At(I) species, namely $\mathrm{At}^{+}$. The existence of this stable monatomic cation in aqueous solution contrasts with lighter halogens. This observation is clear evidence of the metallic behavior of astatine.

In acidic conditions and in the presence of a strong oxidizer, there exists another "metallic" species characterized by a positive charge in electromobility experiments ${ }^{33}$ and in ion exchange chromatography. ${ }^{34}$ The most frequently suggested chemical forms for species III are $\mathrm{At}^{+}, \mathrm{At}^{3+}$ and $\mathrm{AtO}^{+}$. Our experiments have shown that the oxidation of $\mathrm{At}^{+}$involves an exchange of two electrons and two protons (the variation of the apparent potential is $\mathrm{pH}$-dependent). ${ }^{32}$ Therefore, species III cannot be $\mathrm{At}^{+}$or $\mathrm{At}^{3+}$ and we concluded that $\mathrm{AtO}^{+}$is the species in question. At this stage, three oxidation states corresponding to $\mathrm{At}^{-}, \mathrm{At}^{+}$and $\mathrm{AtO}^{+}$were elucidated at $\mathrm{pH}$ between 1 and 2. Under standard conditions $(298.15 \mathrm{~K}, 1 \mathrm{M})$, the redox potentials are $0.36 \pm 0.01 \mathrm{~V}$ and 0.74 $\pm 0.01 \mathrm{~V} v s . \mathrm{SHE}$ for the $\mathrm{At}^{+} / \mathrm{At}^{-}$and $\mathrm{AtO}^{+} / \mathrm{At}^{+}$couples, respectively. ${ }^{32}$

In oxidizing conditions and when the $\mathrm{pH}$ increases, the conversion of $\mathrm{AtO}^{+}$to a neutral species was observed by ion exchange chromatography. ${ }^{34}$ The change in speciation was also observed using Schubert's method. Quantitative interpretation of the data showed the exchange of one proton and thus the formation of the $\mathrm{AtO}(\mathrm{OH})$ hydrolyzed species. This conclusion was supported by the thermodynamic constants predicted by DFT calculations. A similar strategy was used to highlight the formation with increasing $\mathrm{pH}$ of a second hydrolyzed species, $\mathrm{AtO}(\mathrm{OH})_{2}^{-}$, in place of a deprotonation of $\mathrm{AtO}(\mathrm{OH}){ }^{3}$ Conversely, experimental studies have not 
been able to reveal hydrolyzed forms of $\mathrm{At}^{+}$, testifying to a narrow domain of existence of $\mathrm{At}^{+}$as shown in Figure 3.

\subsection{Metallic properties of $\mathrm{At}^{+}$and $\mathrm{AtO}^{+}$}

The interactions between $\mathrm{At}^{+}$or $\mathrm{AtO}^{+}$, jointly denoted $\mathrm{At}(\mathrm{x})^{+}$, and common inorganic ligands (e.g., $\mathrm{Cl}^{-}, \mathrm{Br}^{-}, \mathrm{I}^{-}$and $\mathrm{SCN}^{-}$) were investigated using our experiment/theory approach. ${ }^{22,23,35,36}$ Binary species with 1:1 and 1:2 stoichiometries were evidenced, highlighting a metallic character for $\operatorname{At}(x)^{+}$. In particular, relativistic DFT calculations show hypervalent astatine atoms for the 1:2 structures. In addition, an experimental study guided by theoretical calculations has evidenced a ternary trihalogen species: based on the equilibrium constant computed for the formation of the $\mathrm{IAtBr}^{-}$species $\left(10^{6.9}\right)$, a narrow domain of existence was anticipated in aqueous solutions. Considering an astatine aqueous solution with finely tuned $E_{\mathrm{H}}, \mathrm{pH}$ and $\mathrm{Br}^{-}$concentration, the experimental results confirmed the formation of a new species when increasing $\mathrm{I}^{-}$concentration. A thermodynamic model that considers the formation of $\mathrm{IAtBr}^{-}$, with an equilibrium constant of $10^{7.5 \pm 0.2}$, can then describe the experimental data. $\mathrm{IAtBr}^{-}$is not only the heaviest possible triatomic interhalogen, but it is also the first one declared with a stability domain in aqueous solution. ${ }^{35}$

It also emerges from theoretical calculations that the solvent has an important influence on the chemistry of astatine at the molecular level. Regarding the reaction between $\mathrm{AtO}^{+}$and $\mathrm{SCN}^{-23}$ the solvation completely change the active site within the molecular cation, from the oxygen atom, which controls the reaction in gas phase, to the astatine atom, when solvated (Figure 4). 


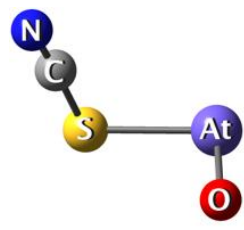

$0 \%$

$75 \%$

$9 \%$

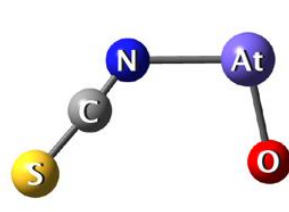

$0 \%$

$25 \%$

$91 \%$

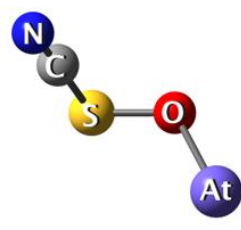

$100 \%$

$0 \%$

$0 \%$

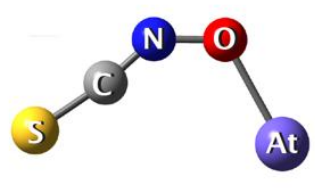

$0 \%$ isolated state

sophistication degree

$0 \%+$ solvation effects

$0 \%+$ SOC effects

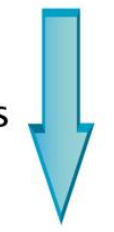

Figure 4. Computed proportions of adducts between $\mathrm{AtO}^{+}$and $\mathrm{SCN}^{-}$. Data from ref. 23.

Regarding the non-bonded $\mathrm{AtO}^{+}$cation, the solvation is also responsible for a rare phenomenon: a ground-state reversal. Indeed, relativistic quantum mechanical calculations have shown that the closed-shell component of the ${ }^{1} \Delta$ excited state in the free cation gradually becomes the essentially-spin-singlet electronic ground state when $\mathrm{AtO}^{+}$interacts with an increasing number of water molecules. ${ }^{36-39}$ It is worth noting that the proximity between the ground state and the first excited electronic states, responsible for this reversal, is also a common property of metals. In addition, according to recent electronic structure calculations, ${ }^{40}$ astatine in condensed state becomes monatomic and simultaneously metallic, conversely to lighter halogens.

\section{Astatine also behaves as a halogen}

The position of astatine in the periodic table of elements (PTE), as a member of the nonmetallic elements that constitute the group 17 (including fluorine, chlorine, bromine and iodine), suggests that it belongs to the halogen family. This assumption is supported by experimental observations, including some of our recent results among the most significant.

\section{II.1 Astatide and related properties}


A characteristic of halogens is their ability to form a stable halide ion in aqueous solution. The construction of the Pourbaix diagram confirmed the existence of the astatide anion, $\mathrm{At}^{-29,30}$ In line with the trend observed within the halogen series, the heavier the halogenide, the more restricted the $E_{\mathrm{H}}-\mathrm{pH}$ stability range. The specific stability of halide ions derives from the electronic configuration of all halogens. They carry seven valence electrons in their outermost electron shell and tend towards holding one more electron, as in the rare gas next to it in the PTE. This is quantitatively reflected by the electron affinity (EA). The halogens exhibit the largest EAs in the PTE but astatine's EA was still unknown 80 years after its discovery. Thanks to the CERN nuclear-physics facility and our contribution to quantum mechanical calculations to guide the experimental setup, this most fundamental atomic property has recently been measured. $^{2}$ Although the value, $2.41578(7) \mathrm{eV}$, is smaller than those of lighter halogens, it remains larger than measured values for all other elements.

If a high EA reflects the strong tendency to form anions in aqueous solution, its value also impacts several properties of atoms relevant to various chemical concepts. Electronegativity is the most prominent example. Its value for astatine, also relying on the recently determined ionization energy (IE), ${ }^{12}$ is presented in Table 1 together with the softness, hardness, and electrophilicity indices. Taken together, these new data are highly relevant in the context of radiolabeling chemistry that has mainly involved nucleophilic and electrophilic astatine species to form covalent bonds for the preparation of radiopharmaceuticals, but also when studying in vivo mechanisms that release $\mathrm{At}^{-}$from the carrier biomolecules.

Table 1. Astatine's atomic properties derived from the high-precision measurements of EA and IE, compared to those of iodine. Data from ref. 2, 12. 


\begin{tabular}{lccc}
\hline Property & Definition & At & I \\
\hline electronegativity & $\chi=\frac{I E+E A}{2}$ & $5.87 \mathrm{eV}$ & $6.76 \mathrm{eV}$ \\
hardness & $\begin{array}{l}\eta \\
\text { softness }\end{array}$ & $3.45 \mathrm{eV}$ & $3.70 \mathrm{eV}$ \\
electrophilicity & $S=\frac{1}{2 \eta}$ & $0.145 \mathrm{eV}^{-1}$ & $0.135 \mathrm{eV}^{-1}$ \\
& $\omega=\frac{\chi^{2}}{2 \eta}$ & $4.99 \mathrm{eV}$ & $6.17 \mathrm{eV}^{2}$ \\
\end{tabular}

\section{II.2 Astatine as the strongest halogen-bond donor}

A noticeable property specific to halogens is their ability to form so-called halogen-bond (XBs). In short, XBs are attractive and highly directional non-covalent interactions formed between an electrophilic region of the halogen atom $\mathrm{X}$ (called $\sigma$-hole) in a $\mathrm{R}-\mathrm{X}$ compound, and a nucleophilic site of a Lewis base. Halogen bonding is recognized as playing an important role in many fields related to molecular recognition, including medicinal, supra-molecular, and materials chemistry, apart from its role in catalysis. ${ }^{41}$ Fluorine, chlorine, bromine and iodine are $\mathrm{XB}$ donors with an ability that increases with increasing atom polarizability and decreasing atom electronegativity, i.e., $\mathrm{F}<\mathrm{Cl}<\mathrm{Br}<\mathrm{I}$. Astatine was expected from early theoretical studies to be the strongest XB donor atom, ${ }^{42,43}$ despite the persistent lack of experimental data. ${ }^{41}$ We reported in 2018 the first characterization of XBs involving At through the formation of adducts between astatine monoiodide (AtI) and nine Lewis bases. ${ }^{1}$ The agreement between the measured equilibrium constants and the computed ones for the formation of At-mediated XB complexes allowed us to unambiguously identify each adduct (Figure 5). This work and the next ones confirmed the highest donating ability of astatine, especially compared to iodine. ${ }^{44}$ Practical interests of this high ability to form XB exist for the improvement of ${ }^{211}$ At-labeling strategies. 
Indeed, an At-mediated XB may explain the robust radiolabeling of bis-(nidocarboranylmethyl)benzene derivatives previously considered as coupling reagents. ${ }^{45}$
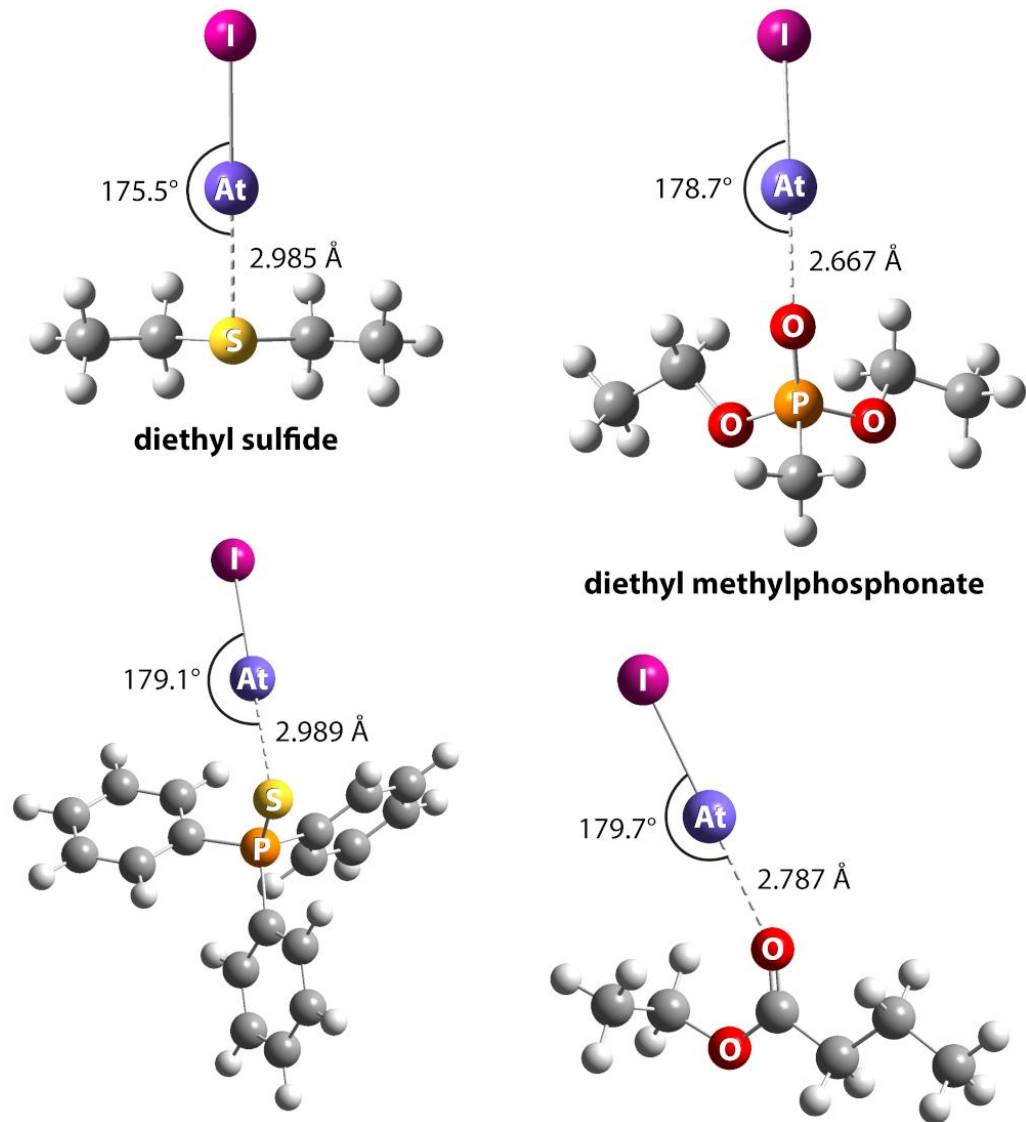

triphenylphosphine sulfide

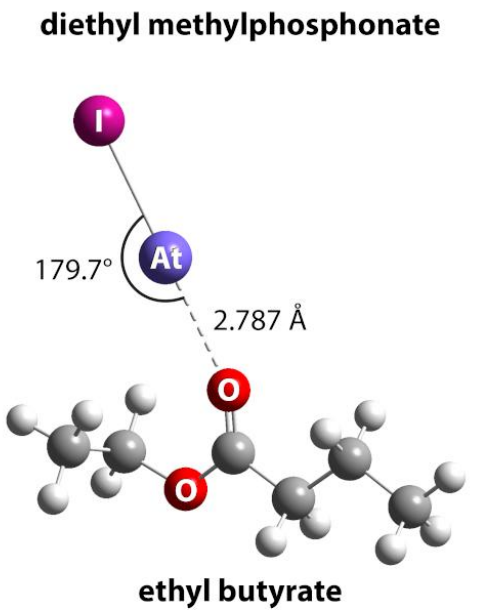

Figure 5. Calculated structures (at the 2c-PW6B95/aug-cc-pVDZ-PP level of theory) of the complexes between astatine monoiodide and Lewis bases. The interaction distances, shorter than the sum of van der Waals radii, and the interaction angles, close to $180^{\circ}$, fulfill the geometrical characteristics of XB interactions. Data from ref. 1.

It is worth noting that some astatinated compounds may form weaker $\mathrm{XB}$ interactions than their iodinated counterparts, e.g., $\mathrm{At}_{2} v s . \mathrm{I}_{2}{ }^{26,46,47}$ Quantum mechanical calculations have evidenced that relativistic effects are responsible for this unexpected behavior. ${ }^{26,27,46}$ Indeed, the 
electrophilicity at the astatine $\sigma$-hole decreases upon the inclusion of SOC, making At a weaker XB donor.

\section{II.3. Charge-shift bonding}

Alongside the two traditional bond families, covalent and ionic, charge-shift (CS) bonds have recently been proposed as a third bonding modality. ${ }^{48}$ For a few $\sigma$-bonds of the general type A$\mathrm{X}$, the bonding itself owes its entire origin to large and dynamic fluctuations of the bonding electron-pair: ${ }^{-} \mathrm{A}\left|\mathrm{X}^{+} \leftrightarrow \mathrm{A}-\mathrm{X} \leftrightarrow{ }^{+} \mathrm{A}\right| \mathrm{X}^{-}$. This CS mechanism is connected to the lone-pair bond-weakening effect (LPBWE), i.e. repulsions between the bonding electrons and the lonepairs adjacent to the bond, which have the same symmetry as the bond (here $\sigma$ ). The optimal covalent-ionic mixing results in a tremendous resonance energy. CS bonding was first characterized in homopolar and heteropolar bonds involving fluorine. ${ }^{49}$ Indeed, electronegative and/or lone-pair-rich elements such as halogens are prone to form CS bonds. Among the theoretical tools for chemical bond analysis, the topological approaches based on the electronic localization function (ELF) and the electron density (QTAIM) are able to reveal the characteristics of CS bonds. ${ }^{48}$ Within these topological approaches, the 3D real-space is divided into mutually disjoint electronic volumes (or basins) that have chemical significance in terms of bonding, lone pairs, core regions, etc. Thanks to recent developments that extended the ELF and QTAIM topological analyses to spin-orbit-coupled wavefunctions, ${ }^{50-52}$ characteristics of CS bonding have been evidenced for some bonds involving astatine. For instance, (i) the hypothetical $\mathrm{At}_{2}$ diatomic molecule do not satisfy the standard QTAIM classification (Figure 6) because of a depleted electron density at midbond $\left(\rho_{\mathrm{cp}}\right)$, associated to a small positive second 
derivative $\left(\nabla^{2} \rho_{\mathrm{cp}}\right),{ }^{53,54}$ and, (ii) regarding heteropolar bonds with carbon atoms or in the AtI species, the electron distribution between the bonding and the valence non-bonding ELF basins displays specific features of LPBWE (revealed by SOC, Figure 6) ${ }^{53}$ The astatine propensity to form CS bonds, greater than iodine, resembles the behavior of the lightest halogens, fluorine and chlorine.

QTAIM descriptors

\begin{tabular}{|c|c|c|c|}
\hline & $\rho_{\mathrm{cp}}$ (а.u.) & $\nabla^{2} \rho_{\text {cp }}$ (a.u.) & delocalization index \\
\hline covalent bonding & $>0.2$ & $<0$ & $\sim$ formal bond order \\
\hline ionic bonding & $<0.1$ & $>0$ & $\sim 0$ \\
\hline $\mathrm{At}_{2}:$ & 0.05 & 0.03 & 0.78 \\
\hline
\end{tabular}

\section{ELF electron populations vs. Lewis pictures}

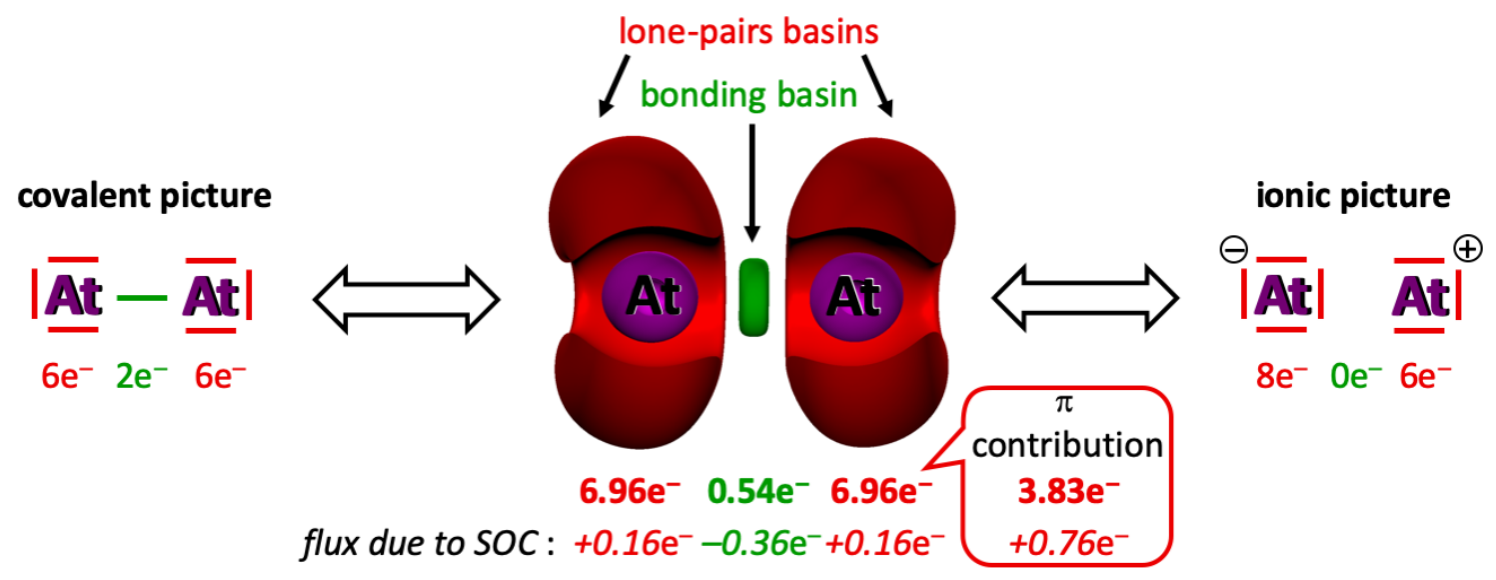

Figure 6. Compared QTAIM and ELF topological analyses of the $\mathrm{At}_{2}$ species. Data from ref. 52, 53.

Detailed ELF and QTAIM topological analyses have shown that the inclusion of SOC in relativistic calculations emphasizes the LPBWE for bonds involving astatine. ${ }^{27,46,47,50-54}$ It turns to an enhanced propensity of astatine to form CS bonds, resulting in a locally decreased 
electrophilicity at the astatine $\sigma$-hole in R-At compounds. Hence, the weakened XB donating ability previously assigned to the relativistic behavior of astatine electron, is eventually connected to the CS character of At-bonds. ${ }^{27,47}$

Overall, the multifaceted character of astatine discussed in this section offers many potential options regarding the preparation of ${ }^{211}$ At-labeled radiopharmaceuticals, from covalent halogen chemistry to metal-ligand coordination, without neglecting the propensity of astatine to form strong XB interactions.

\section{Radiolabeling chemistry with astatine-211: improving methods and in vivo stability III.1. Astatoaryl compounds}

The assumption that astatine would behave similarly to iodine has historically led to radiolabeling strategies consisting in transpositions from well-known radioiodination procedures, with some successes, but also unexpected results. $\mathrm{At}^{-}$and $\mathrm{At}^{+}$are viewed as a typical halogen species in classical nucleophilic and electrophilic reactions used in aryl labeling protocols as discussed in detail elsewhere (Figure 7). ${ }^{6}$ 


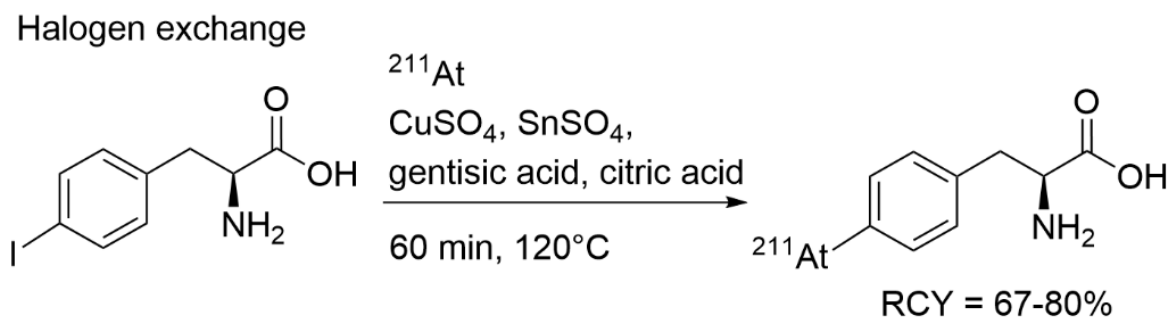

Halodediazotation<smiles>[N+]=[N+]c1ccc(C(=O)O)cc1</smiles>

Halodeprotonation

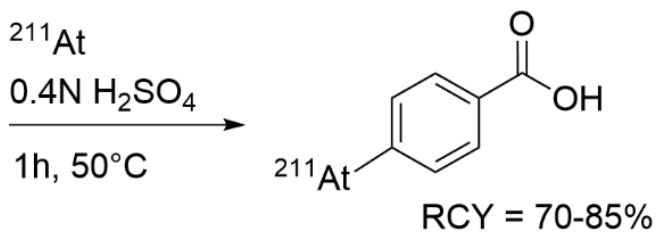<smiles></smiles>

Halodemetallation<smiles></smiles>

$\mathrm{RCY}=68 \%$

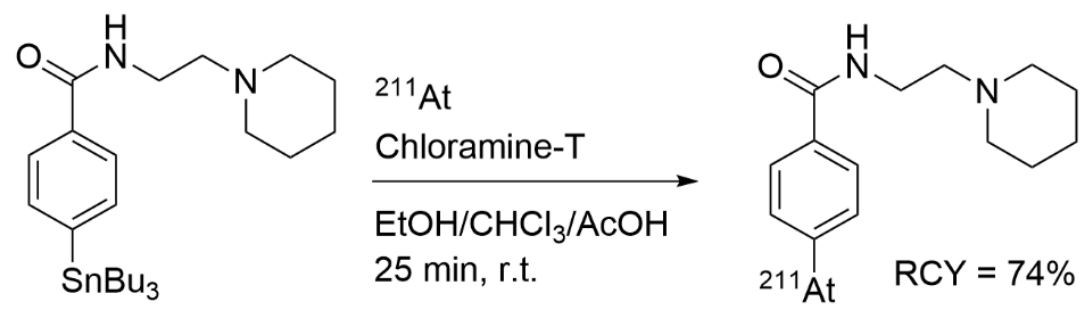

Figure 7. Conventional ${ }^{211}$ At-labeling approaches discussed in ref. 6 .

Conversely, the direct radiolabeling of proteins is a striking example of how astatine can demonstrate unanticipated outcomes. Indeed, early attempts consisted in adapting the wellknown radioiodination of proteins by electrophilic aromatic substitution on tyrosine residues (Figure 8a), ${ }^{55}$ but results were somewhat disappointing. Although radiochemical yields (RCYs) were high $(>80 \%)$, the labeling stability was low, resulting in a fast release of astatine from the protein. $^{56}$ Initially attributed to the supposedly weak At-tyrosine bond, the origin of this instability was latter assumed to arise from the formation of a weak At-sulfur bond with cysteine 
residues. ${ }^{57}$ However, this interpretation deserves to be reconsidered if we look closely at the experimental conditions. In light of the Pourbaix diagram at near neutral $\mathrm{pH}$ and oxidizing conditions, $\mathrm{AtO}^{+}$or an hydrolyzed form of $\mathrm{AtO}^{+}$is most probably the involved species that binds to proteins. Our DFT calculations support interactions with thiol-containing molecules via the oxygen atom in $\mathrm{AtO}^{+}$, leading to a $\mathrm{O}-\mathrm{S}$ covalent bond. ${ }^{58}$

The strategies developed after these initial attempts consisted in two-step procedures, i.e. the synthesis of stable astatoaryl prosthetic groups followed by their conjugation to the protein. The main approach developed by Wilbur and Zalutsky uses $N$-succinimidyl-[ $\left[{ }^{211} \mathrm{At}\right]$ astatobenzoate $\left(\left[{ }^{211} \mathrm{At}\right] \mathrm{SAB}\right)$ - obtained by electrophilic astatodemetallation of the organotin precursor - which is then conjugated to the amino groups of lysines residues (Figure 8b). ${ }^{59}$ The method has become a gold standard, applied in the first clinical trial with ${ }^{211} \mathrm{At}^{9}{ }^{9}$ and that we also used in our early investigations. ${ }^{60}$ But we faced limits, in particular reproducibility issues mostly due to the lack of robustness of the required electrophilic species, owing to (i) its restricted $E_{\mathrm{H}} \mathrm{pH}$ range of existence, in addition to (ii) radiolysis issues leading over time to changes in astatine speciation. ${ }^{61}$ Furthermore, another limit is the suboptimal bioconjugation step yield (50\% to $75 \%$ at best) which lowers the overall procedure efficiency. From these observations, we started a series of investigations aiming at improving the access to ${ }^{211}$ At-labeled antibodies. 
a) Direct radiohalogenation

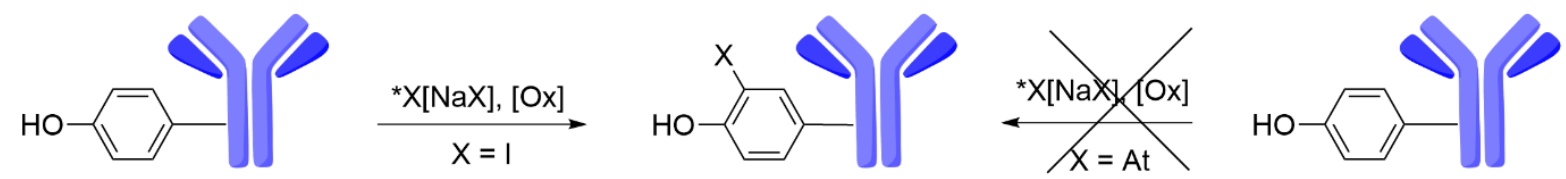

b) Two-step radiolabeling via $\left[{ }^{211} \mathrm{At}\right] \mathrm{SAB}$ prosthetic group

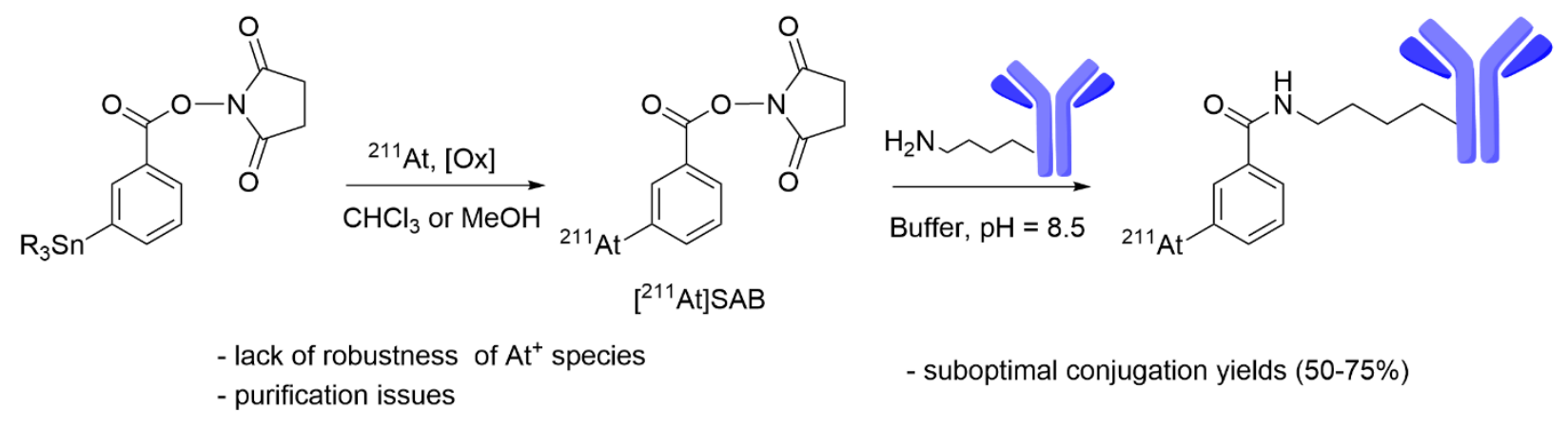

Figure 8. Early developed protocols for ${ }^{211}$ At-labeling of proteins.

Ionic liquid organotin precursors. A critical step in conventional $\left[{ }^{211} \mathrm{At}\right] \mathrm{SAB}$ radiosynthesis is the purification to remove unreacted astatine, oxidizer and, more importantly, toxic stannylated precursor/side products. This is usually performed using HPLC, but at the cost of a lengthy step and considerable retention of radiolabeled product in the chromatographic system. Simplified purification steps can be achieved using resin supported precursors, as demonstrated with the preparation of meta- $\left[{ }^{211} \mathrm{At}\right]$ astatobenzylguanidine for the treatment of neuroendocrine tumors. ${ }^{62}$ With the perspective of automated $\left[{ }^{211} \mathrm{At}\right] \mathrm{SAB}$ radiosynthesis, we developed a further simplified approach based on the use of an ionic liquid supported organotin compound. ${ }^{63}$ The precursor, obtained in 3 steps from an imidazolium hexafluorophosphate moiety, led to a shorter radiolabeling procedure thanks to faster purification step by filtration on a silica cartridge instead of usual HPLC. Furthermore, the negligible activity retention observed contributed to improved RCYs for the preparation of $\left[{ }^{211} \mathrm{At}\right] \mathrm{SAB}$ and corresponding radioimmunoconjugates (Figure 9). 

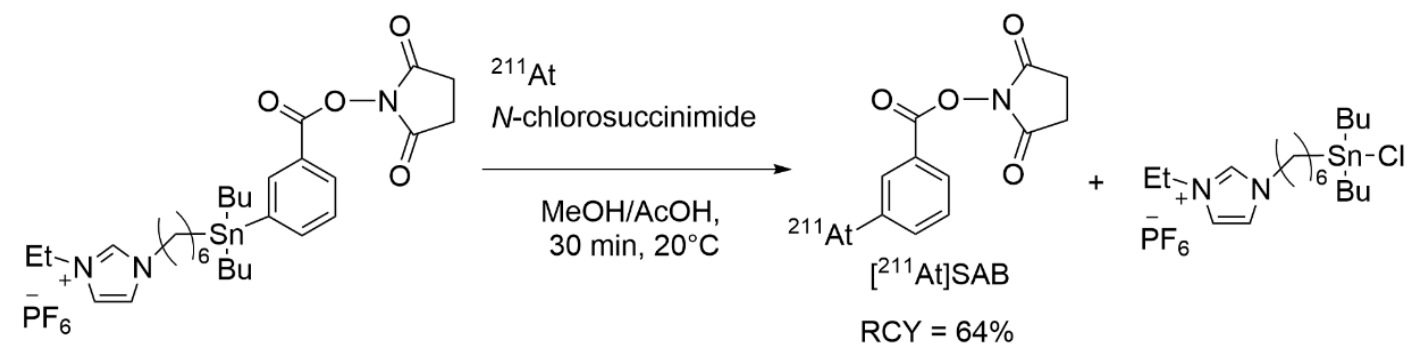

Figure 9. Preparation of $\left[{ }^{211} \mathrm{At}\right] \mathrm{SAB}$ using an ionic liquid supported precursor.

Aryliodonium salts chemistry. Bringing further the idea to move away from astatodestannylation and unstable electrophilic astatine species required, we investigated the use of the $\mathrm{At}^{-}$species and turned our attention to the nucleophilic aromatic substitution of diaryliodonium salts. The reactivity of astatide revealed an unexpected higher reactivity than anticipated from the trend observed with lighter halogens, allowing to develop radiolabeling protocols at a significantly lower temperature and with a broader scope of solvents than radiofluorine and radioiodine. ${ }^{64}$ The reaction was applied to the radiosynthesis of $\left[{ }^{211} \mathrm{At}\right] \mathrm{SAB}$ with the advantage of significantly improved reproducibility and efficiency as well as simplified purification step using silica cartridges instead of HPLC. ${ }^{65}$ The precursor was then used successfully for the ${ }^{211}$ At-labeling of a monoclonal antibody $(\mathrm{mAb})$ in a preclinical study on the treatment of multiple myeloma. ${ }^{66}$ Other prosthetic groups for bioconjugation by click chemistry were also obtained in high RCYs thanks to a high selectivity of substitution towards the aryl position of interest (Figure 10). The astatinated benzylazide and tetrazine compounds led to significantly improved bioconjugation yields $(>90 \%)$, in comparison with the initial $\left[{ }^{211} \mathrm{At}\right] \mathrm{SAB}$ strategy when applied to a mAb respectively preconjugated to strained alkyne and transcyclooctene click chemistry partner moieties. $^{67}$ 


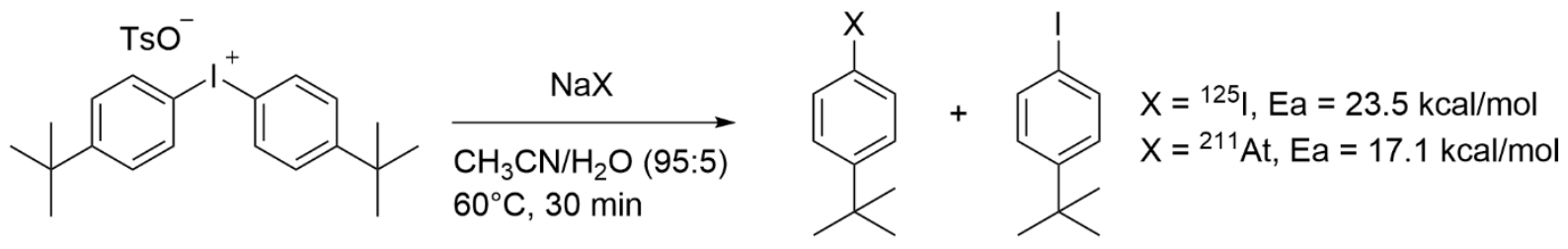

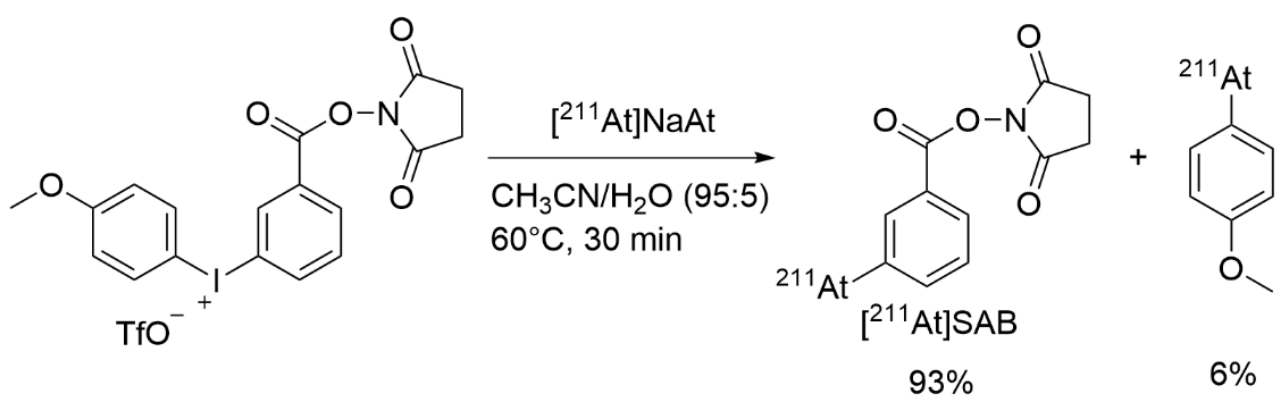<smiles>COc1ccc([I-]([O-])c2cccc(CN)c2)cc1</smiles>

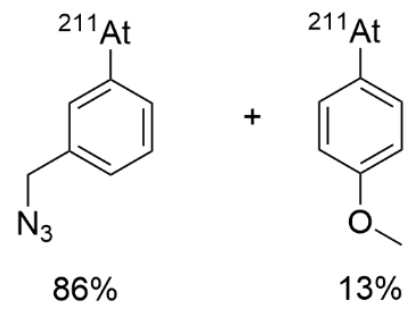

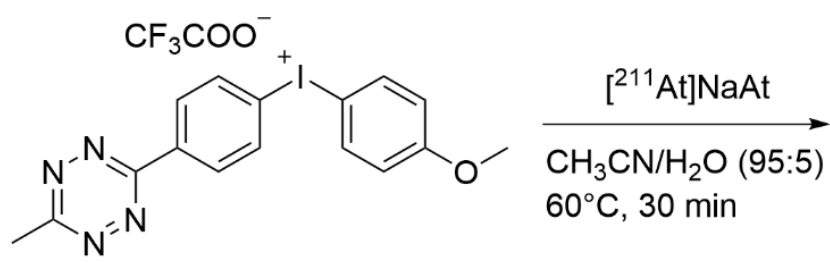<smiles>COc1ccc([Al+]c2ccc([Al+])cc2)cc1</smiles>

Figure 10. Nucleophilic ${ }^{211}$ At-labeling of diaryliodonium salts.

Arylboron chemistry. Whereas aryliodonium salts and click chemistry allowed us to improve both the efficiency and the reproducibility of mAb astatination, they still resulted in time consuming two-step procedures. A one-step approach using mAbs pre-conjugated with the precursor has been reported by Lindegren's group, but it remains based on the use of electrophilic astatodestannylation reaction. ${ }^{68}$ With the aim to reach the optimal method, we continued our investigations on the use of $\mathrm{At}^{-}$. The copper assisted radiohalogenation of arylboron precursors (derived from the Chan-Evans-Lan cross-coupling reaction) has recently 
been reported by other groups. In particular, it was shown that a broad scope of arylboronic esters could be efficiently astatinated at room temperature in organic solvents. ${ }^{69}$ Pushing the investigation further, we found that the reaction, applied to arylboronic acids, could remain highly efficient in aqueous solution even at precursor concentration as low as $250 \mu \mathrm{M}$, provided that a ligand such as 1,10-phenanthroline is added to keep the catalyst active. These conditions, now compatible with proteins, were then applied to a multiple myeloma targeting $\mathrm{mAb}$ preconjugated with an arylboronic acid moiety. An efficient and fast procedure was set up, which outperforms the previously reported ones in terms of RCY, specific activity and protocol duration (Figure 11). ${ }^{4}$ It is furthermore applicable to radioiodination, allowing the development of radiotheranostic pharmaceuticals based on ${ }^{123} \mathrm{I}$ or ${ }^{124} \mathrm{I}$ for imaging the lesions, and on ${ }^{131} \mathrm{I}$ or

${ }^{211}$ At to treat them. ${ }^{70}$ In addition, the long-term storability of the pre-conjugated mAb observed ( $>1$ year) opens possibility to develop radiolabeling kits for easy development in a clinical setting.

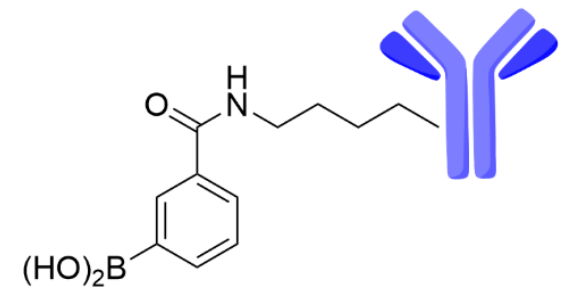

Storable for $>12$ months at $-18^{\circ} \mathrm{C}$ to $+4^{\circ} \mathrm{C}$ in radiolabeling buffer $\left[{ }^{125} \mathrm{I}\right] \mathrm{Nal}$ or $\left[{ }^{211} \mathrm{At}\right] \mathrm{NaAt}$

$\mathrm{Cu}(\mathrm{OTf})_{2} \mathrm{pyr}_{4}$

1,10-phenanthroline

Tris buffer $0.5 \mathrm{M} \mathrm{pH} 6 / \mathrm{DMF}$

(92.5:7.5)

$30 \mathrm{~min}$, r.t.

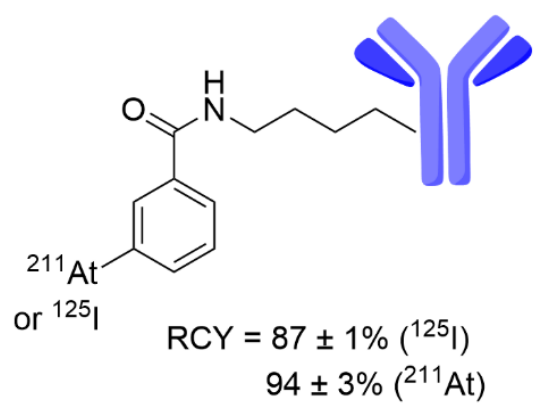

Figure 11. One-step radiohalogenation of a mAb preconjugated to an arylboronic acid moiety.

\section{III.2. Weakness of astatoaryl compounds and alternatives.}

The stability of the carbon-halogen bond decreases with increasing halogen size and increasing carbon hybridization state. We confirmed this trend for astatinated compounds by computing descriptors including bond enthalpies and bond orders, ${ }^{71}$ which supports the initial choice to 
favor astatoaryl compounds. Yet, a number of in vivo studies have highlighted the progressive dissociation of the aryl-At bond, at a significantly higher rate than radioiodinated analogues, especially with small biomolecules or antibody fragments that are rapidly metabolized. This is also true when mAbs are internalized within targeted cells. ${ }^{72}$ Searching for potential deastatination mechanisms led us to consider the role of lysosomes found within cells and associated to acidic and oxidizing conditions. Model experiments including incubation of 3ethylastatobenzoate in oxidizing, Fenton-like conditions, evidenced a significantly faster release of free astatine compared to the radioiodinated analogue, suggesting that oxidation plays an important role in deastatination (Figure 12). This hypothesis is supported by the calculated IE of halobenzoates, suggesting a facilitated oxidation of the astatinated derivative, and the lower C-At bond dissociation energy (BDE) for the resulting oxidized form, compared to the iodine analogue. $^{73}$ 
a)

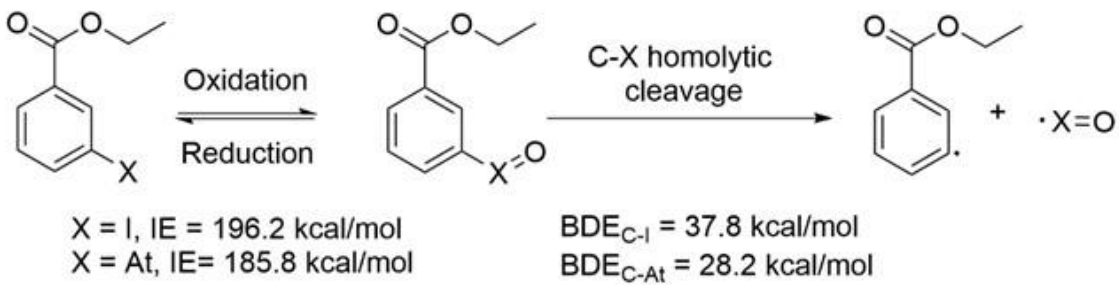

b)

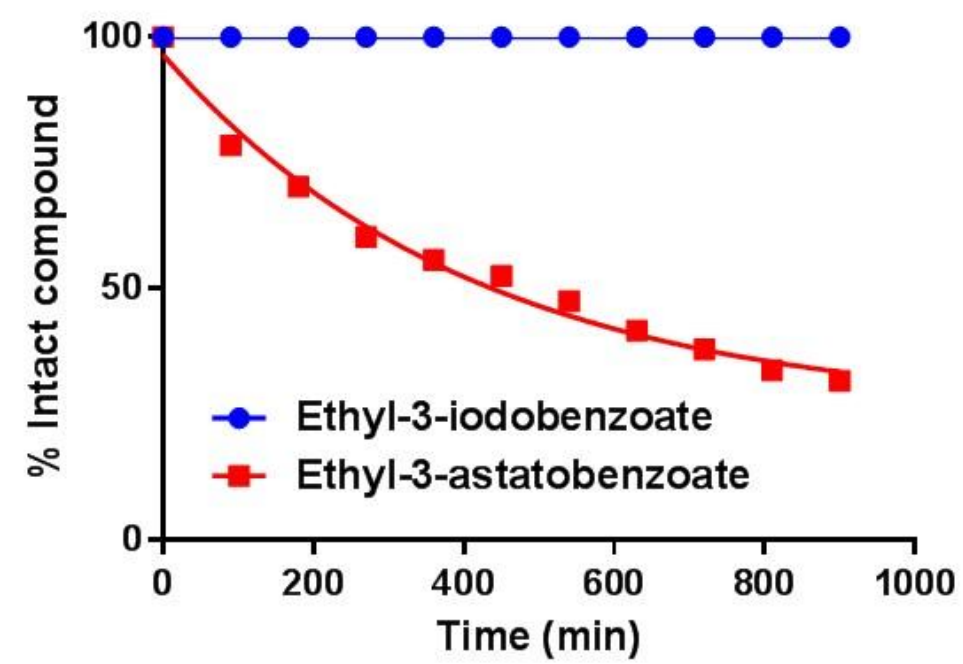

Figure 12. a) Proposed oxidative mechanism leading to C-At bond dissociation in vivo. b) Stability of halobenzoate derivatives submitted to Fenton-like oxidative conditions. Data from ref. 73 .

Whereas reported modulations of the astatoaryl structure have not yet clearly improved in vivo stability, this issue may be addressed by using interactions other than the covalent $\mathrm{C}-\mathrm{At}$ bond. Exploiting the metallic properties of electrophilic astatine was pioneered by Ludwig et al. through complexation studies with thioether ligands, ${ }^{74}$ as well as subsequent attempts with wellknown metal chelators such as DTPA. ${ }^{75}$ However, none have yet led to in vivo stable products, their biodistribution patterns in mice being nearly identical to sodium astatide. The most successful alternative to date was developed by Wilbur's group. It relies on the formation of a covalent B-At bond with boron clusters. ${ }^{72}$ In particular the decaborate moiety drastically reduced 
in vivo release of At compared to astatoaryl (reduced activity uptake in target organs of free astatine such as thyroid (neck), stomach, lungs or spleen in Figure 13). Our DFT calculations allowed to establish a relationship between the $\mathrm{B}-\mathrm{At}$ and $\mathrm{C}-\mathrm{At}$ bond enthalpies and in vivo stability, the higher the bond enthalpy the lower the content of released astatine being trapped by the thyroid. ${ }^{76}$ However, this chemistry may impair the pharmacokinetics of the carrier compounds, probably due to the double negative charge on the boron cluster. ${ }^{77}$

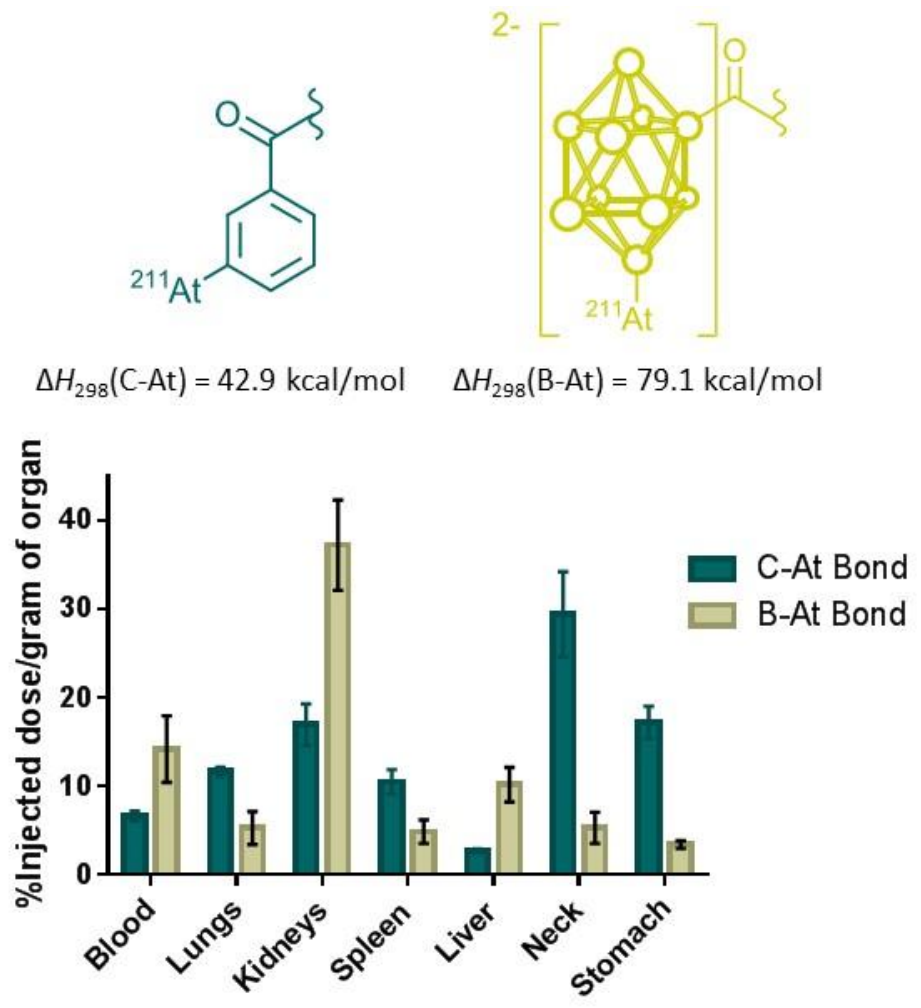

Figure 13. Boron cluster vs astatoaryl stability. Data from ref. 76, 78.

Astatine being a soft base like iodine (Table 1), investigations of the interaction between astatide and soft metal cations recently emerged. Pruszyńsky reported the investigation of astatide as a ligand of rhodium(III) and iridium(III) metal centers trapped within a polythioether chelating agent (Figure 14). However, applications on the radiolabeling of relevant biomolecule has not yet proven more stability than the use of astatoaryl prosthetic groups. ${ }^{79}$ Looking for 
softer metallic centers, we used rhodium(I) complexed within a $N$-heterocyclic carben ligand (NHC), and we introduced astatide as a ligand by nucleophilic substitution of a chloride, leading to a compound that was highly stable in human blood serum. ${ }^{80}$ The impact of the nature of the metal and of NHC ligands on the metal-At bond stability is currently under investigation.
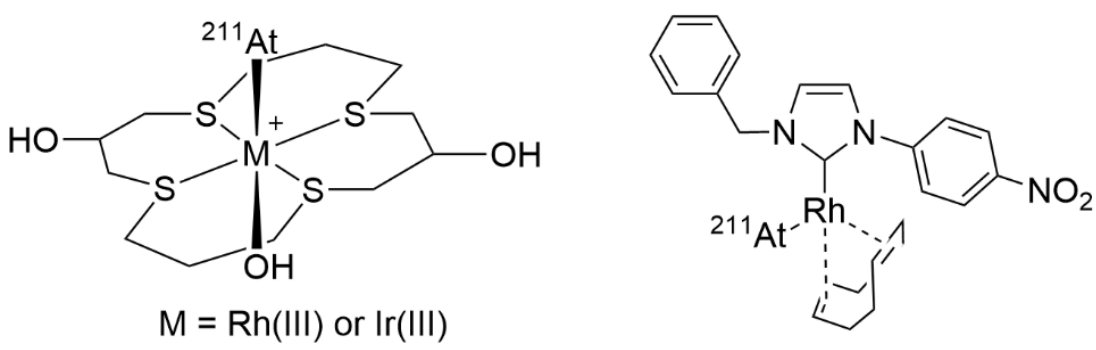

Figure 14. Complexes with astatine-metal covalent bond.

\section{Conclusion}

Over the past decade, we have taken research on astatine from an all-empirical work, relying on extrapolations from lighter halogens, to a new era where computer assisted experimentation has revealed unanticipated findings. If the construction of the Pourbaix diagram has confirmed both metallic and halogen behavior of astatine, its expected superiority in the field of halogenbond interactions is also ambiguous. Just as Janus presents two faces (one turned to the past, the other to the future), astatine seems to have two antinomic characters with charge-shift bonding that hinders halogen bonding. This duality stands as a whole for astatine, unquestionably the last naturally occurring element of the halogen family, which however exhibits simultaneously a metallic character. Is the final option to merge astatine into the metalloid family? Based on current knowledge, this question probably cannot be definitively answered ${ }^{81}$ Fortunately, the growing community having access to this rare radioelement will certainly accelerate discoveries in the coming decade and contribute in solving the puzzle of astatine. 
Even if insufficiently defined, astatine's multifaceted character is fortunate because it allows as many possibilities to improve radiolabeling chemistry as illustrated with the novel approaches discussed herein. These methods, in particular the ready-to-use arylboron chemistry, should ease the clinical transfer of alpha emitters-based radiopharmaceuticals by lifting logistical obstacles currently encountered. With an increasing knowledge on astatine chemical properties allowing for the development of rationally designed labeling procedures, it makes no doubt that applications on ${ }^{211}$ At-based cancer therapy will be facilitated in the near future.

\section{Biographies}

François Guérard received his Ph.D. in chemistry from the University of Nantes (France) in 2010. He then joined the Brechbiel's group (National Cancer Institute, USA) to develop ${ }^{89} \mathrm{Zr}$ labeling chemistry. In 2017, he was appointed CNRS research associate at Inserm (Nantes), in the Nuclear Oncology Group where he leads a research program on ${ }^{211}$ At-labeling chemistry.

Clémence Maingueneau received her Ph.D. in chemistry from the University of Caen Normandie (France) in 2019. Currently, she is a postdoctoral fellow in the Nuclear Oncology Group (Inserm, Nantes). Her research interests focus on ${ }^{211}$ At-labeling chemistry.

Lu Liu received her Ph.D. in analytical chemistry and Radiochemistry from IMT Atlantique (Nantes, France) in 2020. Her research focus on the fundamental aspects of astatine chemistry, including its speciation and reactivity in solutions.

Romain Eychenne received his Ph.D. in chemistry from the University of Toulouse (France) in 2017. He is currently a research engineer at the Arronax cyclotron facility, with a focus on radiopharmaceutical chemistry and especially ${ }^{211}$ At-labeling chemistry.

Jean-François Gestin received his Ph.D. in chemistry from the University of Nantes (France) in 1990 after spending one year at CEA (France) and two years at Brookhaven National Laboratory 
(USA). He then joined Chatal's group at Inserm (Nantes, France) in 1991, where he set up the chemistry and radiopharmacy group.

Gilles Montavon received his Ph.D. in radiochemistry from the University of Paris-Sud in 1996.

Since 1998, he is a CNRS researcher in the radiochemistry group at Subatech laboratory where he leads a team interested in the behavior of radioelements at ultra-trace concentrations for medical and environmental issues.

Nicolas Galland received his Ph.D. in physical chemistry from the University of Bordeaux (France) in 2002. Since 2003, he is an associate professor at University of Nantes (France). His research interests include modeling non-covalent interactions (hydrogen and halogen bonds) and the development of novel tools for bonding analysis in compounds containing heavy atoms.

\section{Acknowledgment}

This work was supported by grants from the French National Agency for Research called “Investissements d'Avenir", Equipex Arronax-Plus (ANR-11-EQPX-0004), Labex IRON (ANR11-LABX-18-01), ISITE NExT (ANR-16-IDEX-0007) and INCa-DGOSInserm_12558.

\section{References}

(1) Guo, N.; Maurice, R.; Teze, D.; Graton, J.; Champion, J.; Montavon, G.; Galland, N. Experimental and Computational Evidence of Halogen Bonds Involving Astatine. Nat. Chem. 2018, 10, 428-434. https://doi.org/10.1038/s41557-018-0011-1.

(2) Leimbach, D.; Karls, J.; Guo, Y.; Ahmed, R.; Ballof, J.; Bengtsson, L.; Boix Pamies, F.; Borschevsky, A.; Chrysalidis, K.; Eliav, E.; Fedorov, D.; Fedosseev, V.; Forstner, O.; Galland, N.; Garcia Ruiz, R. F.; Granados, C.; Heinke, R.; Johnston, K.; Koszorus, A.; Köster, U.; Kristiansson, M. K.; Liu, Y.; Marsh, B.; Molkanov, P.; Pašteka, L. F.; Ramos, J. P.; Renault, E.; Reponen, M.; Ringvall-Moberg, A.; Rossel, R. E.; Studer, D.; Vernon, A.; Warbinek, J.; Welander, J.; Wendt, K.; Wilkins, S.; Hanstorp, D.; Rothe, S. The Electron Affinity of Astatine. Nat. Commun. 2020, 11, 3824. https://doi.org/10.1038/s41467-020-17599-2. 
(3) Sergentu, D.-C.; Teze, D.; Sabatié-Gogova, A.; Alliot, C.; Guo, N.; Bassal, F.; Silva, I. D.; Deniaud, D.; Maurice, R.; Champion, J.; Galland, N.; Montavon, G. Advances on the Determination of the Astatine Pourbaix Diagram: Predomination of $\mathrm{AtO}(\mathrm{OH})_{2}{ }^{-}$over $\mathrm{At}^{-}$ in Basic Conditions. Chem. Eur. J. 2016, 22, 2964-2971. https://doi.org/10.1002/chem.201504403.

(4) Berdal, M.; Gouard, S.; Eychenne, R.; Marionneau-Lambot, S.; Croyal, M.; FaivreChauvet, A.; Chérel, M.; Gaschet, J.; Gestin, J.-F.; Guérard, F. Investigation on the Reactivity of Nucleophilic Radiohalogens with Arylboronic Acids in Water: Access to an Efficient Single-Step Method for the Radioiodination and Astatination of Antibodies. Chem. Sci. 2021, 12, 1458-1468. https://doi.org/10.1039/D0SC05191H.

(5) Corson, D. R.; MacKenzie, K. R.; Segrè, E. Possible Production of Radioactive Isotopes of Element 85. Phys. Rev. 1940, 57, 1087.

(6) Guérard, F.; Gestin, J.-F.; Brechbiel, M. W. Production of $\left[{ }^{211}\right.$ At $]$-Astatinated Radiopharmaceuticals and Applications in Targeted $\alpha$-Particle Therapy. Cancer Biother. Radiopharm. 2013, 28, 1-20. https://doi.org/10.1089/cbr.2012.1292.

(7) Guerard, F.; Barbet, J.; Chatal, J. F.; Kraeber-Bodere, F.; Cherel, M.; Haddad, F. Which Radionuclide, Carrier Molecule and Clinical Indication for Alpha-Immunotherapy? J. Nucl. Med. Mol. Imaging 2015, 59, 161-167.

(8) Baidoo, K. E.; Yong, K.; Brechbiel, M. W. Molecular Pathways: Targeted $\alpha$-Particle Radiation Therapy. Clin. Cancer Res. 2013, 19, 530-537. https://doi.org/10.1158/10780432.CCR-12-0298.

(9) Zalutsky, M. R.; Reardon, D. A.; Akabani, G.; Coleman, R. E.; Friedman, A. H.; Friedman, H. S.; McLendon, R. E.; Wong, T. Z.; Bigner, D. D. Clinical Experience with Alpha-Particle Emitting ${ }^{211}$ At: Treatment of Recurrent Brain Tumor Patients with ${ }^{211}$ AtLabeled Chimeric Antitenascin Monoclonal Antibody 81C6. J. Nucl. Med. 2008, 49, 3038. https://doi.org/10.2967/jnumed.107.046938.

(10) Hallqvist, A.; Bergmark, K.; Bäck, T. A.; Andersson, H.; Dahm-Kähler, P.; Johansson, M.; Lindegren, S.; Jensen, H.; Jacobsson, L.; Hultborn, R.; Palm, S.; Albertsson, P. Intraperitoneal Alpha-Emitting Radio Immunotherapy with Astatine-211 in Relapsed Ovarian Cancer; Long-Term Follow-up with Individual Absorbed Dose Estimations. $J$. Nucl. $\quad$ Med. 2019, 60, 1073-1079. jnumed.118.220384. https://doi.org/10.2967/jnumed.118.220384.

(11) Wilbur, D. S. Enigmatic Astatine. Nat. Chem. 2013, 5, 246-246. https://doi.org/10.1038/nchem.1580.

(12) Rothe, S.; Andreyev, A. N.; Antalic, S.; Borschevsky, A.; Capponi, L.; Cocolios, T. E.; De Witte, H.; Eliav, E.; Fedorov, D. V.; Fedosseev, V. N.; Fink, D. A.; Fritzsche, S.; Ghys, L.; Huyse, M.; Imai, N.; Kaldor, U.; Kudryavtsev, Y.; Köster, U.; Lane, J. F. W.; Lassen, J.; Liberati, V.; Lynch, K. M.; Marsh, B. A.; Nishio, K.; Pauwels, D.; Pershina, V.; Popescu, L.; Procter, T. J.; Radulov, D.; Raeder, S.; Rajabali, M. M.; Rapisarda, E.; Rossel, R. E.; Sandhu, K.; Seliverstov, M. D.; Sjödin, A. M.; Van den Bergh, P.; Van Duppen, P.; Venhart, M.; Wakabayashi, Y.; Wendt, K. D. A. Measurement of the First Ionization Potential of Astatine by Laser Ionization Spectroscopy. Nat. Commun. 2013, 4, 1835. https://doi.org/10.1038/ncomms2819.

(13) Visser, G. W. Inorganic Astatine Chemistry Part II: The Chameleon Behaviour and Electrophilicity of At-Species. Radiochim. Acta 1989, 47, 97-103. 
(14) Haddad, F.; Barbet, J.; Chatal, J.-F. The ARRONAX Project. Curr. Radiopharm. 2011, 4, 186-196. https://doi.org/10.2174/1874471011104030186.

(15) Lindegren, S.; Albertsson, P.; Bäck, T.; Jensen, H.; Palm, S.; Aneheim, E. Realizing Clinical Trials with Astatine-211: The Chemistry Infrastructure. Cancer Biother. Radiopharm. 2020, 35, 425-436. https://doi.org/10.1089/cbr.2019.3055.

(16) Appelman, E. H. The Oxidation States of Astatine in Aqueous Solution. J. Am. Chem. Soc. 1961, 83, 805-807. https://doi.org/10.1021/ja01465a014.

(17) Visser, G. W.; Diemer, E. L. Inorganic Astatine Chemistry: Formation of Complexes of Astatine. Radiochim. Acta 1983, 33, 145-151.

(18) Cavallero, A.; Roessler, K. Behaviour of Astatine in Radiopolarography. Radiochim. Acta 1989, 47, 109-112.

(19) Cavallero, A.; Roessler, K. Chromatography at Fixed Redox Potential of Inorganic Forms of Astatine $\left({ }^{211} \mathrm{At}\right)$. Radiochim. Acta 1989, 47, 113-118. https://doi.org/10.1524/ract.1989.47.23.113.

(20) Nishinaka, I.; Hashimoto, K.; Suzuki, H. Thin Layer Chromatography for Astatine and Iodine in Solutions Prepared by Dry Distillation. J. Radioanal. Nucl. Chem. 2018, 318, 897-905. https://doi.org/10.1007/s10967-018-6088-6.

(21) Schubert, J. The Use of Ion Exchangers of the Determination of Physical-Chemical Properties of Substances, Particularly Radiotracers, in Solution. I. Theoretical. J. Phys. Chem. 1948, 52, 340-350. https://doi.org/10.1021/j150458a006.

(22) Champion, J.; Alliot, C.; Huclier, S.; Deniaud, D.; Asfari, Z.; Montavon, G. Determination of Stability Constants between Complexing Agents and At(I) and At(III) Species Present at Ultra-Trace Concentrations. Inorg. Chim. Acta 2009, 362, 2654-2661. https://doi.org/10.1016/j.ica.2008.12.005.

(23) Champion, J.; Seydou, M.; Sabatié-Gogova, A.; Renault, E.; Montavon, G.; Galland, N. Assessment of an Effective Quasirelativistic Methodology Designed to Study Astatine Chemistry in Aqueous Solution. Phys. Chem. Chem. Phys. 2011, 13, 14984. https://doi.org/10.1039/c1cp20512a.

(24) Maurice, R.; Réal, F.; Gomes, A. S. P.; Vallet, V.; Montavon, G.; Galland, N. Effective Bond Orders from Two-Step Spin-Orbit Coupling Approaches: The $\mathrm{I}_{2}, \mathrm{At}_{2}, \mathrm{IO}^{+}$, and $\mathrm{AtO}^{+}$ Case Studies. J. Chem. Phys. 2015, 142, 094305. https://doi.org/10.1063/1.4913738.

(25) Sergentu, D.-C.; Amaouch, M.; Pilmé, J.; Galland, N.; Maurice, R. Electronic Structures and Geometries of the $\mathrm{XF}_{3}(\mathrm{X}=\mathrm{Cl}, \mathrm{Br}, \mathrm{I}, \mathrm{At})$ Fluorides. J. Chem. Phys. 2015, 143, 114306. https://doi.org/10.1063/1.4930609.

(26) Galland, N.; Montavon, G.; Questel, J.-Y. L.; Graton, J. Quantum Calculations of AtMediated Halogen Bonds: On the Influence of Relativistic Effects. New J. Chem. 2018, 42, 10510-10517. https://doi.org/10.1039/C8NJ00484F.

(27) Graton, J.; Rahali, S.; Questel, J.-Y. L.; Montavon, G.; Pilmé, J.; Galland, N. Spin-Orbit Coupling as a Probe to Decipher Halogen Bonding. Phys. Chem. Chem. Phys. 2018, 20, 29616-29624. https://doi.org/10.1039/C8CP05690K.

(28) Pech, C. G.; Haase, P. A. B.; Galland, N.; Borschevsky, A.; Maurice, R. Relevance of Effective Bond Orders in Heterodiatomic Molecules and Role of the Spin-Orbit Coupling in the $\operatorname{At} X(X=$ At-F $)$ Series. Phys. Rev. A 2019, 100, 032518. https://doi.org/10.1103/PhysRevA.100.032518.

(29) Sabatié-Gogova, A.; Champion, J.; Huclier, S.; Michel, N.; Pottier, F.; Galland, N.; Asfari, Z.; Chérel, M.; Montavon, G. Characterization of At ${ }^{-}$Species in Simple and Biological 
Media by High Performance Anion Exchange Chromatography Coupled to Gamma Detector. Anal. Chim. Acta 2012, 721, 182-188. https://doi.org/10.1016/j.aca.2012.01.052.

(30) Guo, N.; Pottier, F.; Aupiais, J.; Alliot, C.; Montavon, G.; Champion, J. Evidence for the Heaviest Expected Halide Species in Aqueous Solution, $\mathrm{At}^{-}$, by Electromobility Measurements. Inorg. Chem. 2018, 57, 4926-4933. https://doi.org/10.1021/acs.inorgchem.7b03003.

(31) Réal, F.; Gomes, A. S. P.; Martínez, Y. O. G.; Ayed, T.; Galland, N.; Masella, M.; Vallet, V. Structural, Dynamical, and Transport Properties of the Hydrated Halides: How Do At ${ }^{-}$ Bulk Properties Compare with Those of the Other Halides, from F- to I-? J. Chem. Phys. 2016, 144, 124513. https://doi.org/10.1063/1.4944613.

(32) Champion, J.; Alliot, C.; Renault, E.; Mokili, B. M.; Chérel, M.; Galland, N.; Montavon, G. Astatine Standard Redox Potentials and Speciation in Acidic Medium. J. Phys. Chem. A 2010, 114, 576-582. https://doi.org/10.1021/jp9077008.

(33) Milanov, M.; Doberenz, V.; Khalkin, V. A.; Marinov, A. Chemical Properties of Positive Singly Charged Astatine Ion in Aqueous Solution. J. Rad. Nucl. Chem. 1984, 83, 291299. https://doi.org/10.1007/BF02037143.

(34) Champion, J.; Sabatié-Gogova, A.; Bassal, F.; Ayed, T.; Alliot, C.; Galland, N.; Montavon, G. Investigation of Astatine(III) Hydrolyzed Species: Experiments and Relativistic Calculations. J. Phys. Chem. A 2013, 117, 1983-1990. https://doi.org/10.1021/jp3099413.

(35) Guo, N.; Sergentu, D.-C.; Teze, D.; Champion, J.; Montavon, G.; Galland, N.; Maurice, R. The Heaviest Possible Ternary Trihalogen Species, IAtBr ${ }^{-}$, Evidenced in Aqueous Solution: An Experimental Performance Driven by Computations. Angew. Chem. Int. Ed. 2016, 55, 15369-15372. https://doi.org/10.1002/anie.201608746.

(36) Sergentu, D.-C.; Réal, F.; Montavon, G.; Galland, N.; Maurice, R. Unraveling the Hydration-Induced Ground-State Change of $\mathrm{AtO}^{+}$by Relativistic and Multiconfigurational Wave-Function-Based Methods. Phys. Chem. Chem. Phys. 2016, 18, 32703-32712. https://doi.org/10.1039/C6CP05028J.

(37) Ayed, T.; Réal, F.; Montavon, G.; Galland, N. Rationalization of the Solvation Effects on the $\mathrm{AtO}^{+}$Ground-State Change. J. Phys. Chem. B 2013, 117, 10589-10595. https://doi.org/10.1021/jp406803e.

(38) Ayed, T.; Seydou, M.; Réal, F.; Montavon, G.; Galland, N. How Does the Solvation Unveil $\mathrm{AtO}^{+}$Reactivity? J. Phys. Chem. B 2013, 117, 5206-5211. https://doi.org/10.1021/jp401759p.

(39) Pereira Gomes, A. S.; Réal, F.; Galland, N.; Angeli, C.; Cimiraglia, R.; Vallet, V. Electronic Structure Investigation of the Evanescent $\mathrm{AtO}^{+}$Ion. Phys. Chem. Chem. Phys. 2014, 16, 9238-9248. https://doi.org/10.1039/C3CP55294B.

(40) Hermann, A.; Hoffmann, R.; Ashcroft, N. W. Condensed Astatine: Monatomic and $\begin{array}{llllll}\text { Metallic. Phys. Rev. } & \text { 2013, } & 111, & 16404 .\end{array}$ https://doi.org/10.1103/PhysRevLett.111.116404.

(41) Cavallo, G.; Metrangolo, P.; Milani, R.; Pilati, T.; Priimagi, A.; Resnati, G.; Terraneo, G. The Halogen Bond. Chem. Rev. 2016, 116, 2478-2601. https://doi.org/10.1021/acs.chemrev.5b00484.

(42) Alkorta, I.; Blanco, F.; Solimannejad, M.; Elguero, J. Competition of Hydrogen Bonds and Halogen Bonds in Complexes of Hypohalous Acids with Nitrogenated Bases. J. Phys. Chem. A 2008, 112, 10856-10863. https://doi.org/10.1021/jp806101t. 
(43) Hill, J. G.; Hu, X. Theoretical Insights into the Nature of Halogen Bonding in Prereactive Complexes. Chem. Eur. J. 2013, 19, 3620-3628. https://doi.org/10.1002/chem.201204312.

(44) Liu, L.; Guo, N.; Champion, J.; Graton, J.; Montavon, G.; Galland, N.; Maurice, R. Towards a Stronger Halogen Bond Involving Astatine: Unexpected Adduct with $\mathrm{Bu}_{3} \mathrm{PO}$ Stabilized by Hydrogen Bonding. Chem. Eur. J. 2020, 26, 3713-3717. https://doi.org/10.1002/chem.201905389.

(45) Wilbur, D. S.; Zalutsky, M.; Wedge, T. J.; Hawthorne, M. F.; Chyan, M.-K.; Hamlin, D. K.; Kegley, B. B.; Risler, R.; Pathare, P. M.; Quinn, J.; Vessella, R. L.; Foulon, C. Reagents for Astatination of Biomolecules: Comparison of the in Vivo Distribution and Stability of Some Radioiodinated/Astatinated Benzamidyl and Nido-Carboranyl Compounds. Bioconjugate Chem. 2004, 15, 203-223. https://doi.org/10.1021/bc034175k.

(46) Sarr, S.; Graton, J.; Rahali, S.; Montavon, G.; Galland, N. Delocalized Relativistic Effects, from the Viewpoint of Halogen Bonding. Phys. Chem. Chem. Phys. 2021, 23, 4064-4074 https://doi.org/10.1039/D0CP05840H.

(47) Sarr, S.; Graton, J.; Montavon, G.; Pilmé, J.; Galland, N. On the Interplay between Charge- Shift Bonding and Halogen Bonding. Chem. Phys. Chem 2020, 21, 240-250. https://doi.org/10.1002/cphc.201901023.

(48) Shaik, S.; Danovich, D.; Wu, W.; Hiberty, P. C. Charge-Shift Bonding and Its Manifestations in Chemistry. Nat. Chem. 2009, 1, 443-449. https://doi.org/10.1038/nchem.327.

(49) Shaik, S.; Maitre, P.; Sini, G.; Hiberty, P. C. The Charge-Shift Bonding Concept. Electron-Pair Bonds with Very Large Ionic-Covalent Resonance Energies. J. Am. Chem. Soc. 1992, 114, 7861-7866. https://doi.org/10.1021/ja00046a035.

(50) Pilmé, J.; Renault, E.; Ayed, T.; Montavon, G.; Galland, N. Introducing the ELF Topological Analysis in the Field of Quasirelativistic Quantum Calculations. J. Chem. Theory Comput. 2012, 8, 2985-2990. https://doi.org/10.1021/ct300558k.

(51) Amaouch, M.; Sergentu, D.-C.; Steinmetz, D.; Maurice, R.; Galland, N.; Pilmé, J. The Bonding Picture in Hypervalent $\mathrm{XF}_{3}(\mathrm{X}=\mathrm{Cl}, \mathrm{Br}$, I, At) Fluorides Revisited with Quantum Chemical Topology. J. Comput. Chem. 2017, 38, 2753-2762. https://doi.org/10.1002/jcc.24905.

(52) Gomez Pech, C.; Haase, P. A. B.; Sergentu, D.; Borschevsky, A.; Pilmé, J.; Galland, N.; Maurice, R. Quantum Chemical Topology at the Spin-Orbit Configuration Interaction Level: Application to Astatine Compounds. J. Comput. Chem. 2020, 41, 2055-2065. https://doi.org/10.1002/jcc.26373.

(53) Pilmé, J.; Renault, E.; Bassal, F.; Amaouch, M.; Montavon, G.; Galland, N. QTAIM Analysis in the Context of Quasirelativistic Quantum Calculations. J. Chem. Theory Comput. 2014, 10, 4830-4841. https://doi.org/10.1021/ct500762n.

(54) Amaouch, M.; Renault, E.; Montavon, G.; Galland, N.; Pilmé, J. Quantum Chemical Topology in the Field of Quasirelativistic Quantum Calculations. In Applications of Topological Methods in Molecular Chemistry; Chauvin, R., Lepetit, C., Silvi, B., Alikhani, E., Eds.; Challenges and Advances in Computational Chemistry and Physics; Springer International Publishing: Cham, 2016; Vol. 22, pp 553-582. https://doi.org/10.1007/978-3-319-29022-5_20.

(55) Greenwood, F.; Hunter, W.; Glover, J. The Preparation of ${ }^{131}$ I-Labelled Human Growth Hormone of High Specific Radioactivity. Biochem. J. 1963, 89, 114-123. https://doi.org/10.1042/bj0890114. 
(56) Aaij, C.; Tschroots WRJM; Lindner, L.; Feltkamp, T. E. The Preparation of Astatine Labelled Proteins. Int. J. Appl. Radiat. Isot. 1975, 26, 25-30.

(57) Visser, G. W. M.; Diemer, E. L.; Kaspersen, F. M. The Nature of the Astatine-Protein Bond. Int. J. Appl. Radiat. Isot. 1981, 32, 905-912. https://doi.org/10.1016/0020708X(81)90077-6.

(58) Bassal, F.; Champion, J.; Pardoue, S.; Seydou, M.; Sabatié-Gogova, A.; Deniaud, D.; Questel, J.-Y. L.; Montavon, G.; Galland, N. Questioning the Affinity of Electrophilic Astatine for Sulfur-Containing Compounds: Unexpected Bindings Revealed. Inorg. Chem. 2020, 59, 13923-13932. https://doi.org/10.1021/acs.inorgchem.0c01553.

(59) Zalutsky, M. R.; Garg, P. K.; Friedman, H. S.; Bigner, D. D. Labeling Monoclonal Antibodies and $\mathrm{F}(\mathrm{Ab})_{2}$ Fragments with the Alpha-Particle-Emitting Nuclide Astatine211: Preservation of Immunoreactivity and in Vivo Localizing Capacity. Proc. Natl. Acad. Sci. U.S.A 1989, 86, 7149-7153. https://doi.org/10.1073/pnas.86.18.7149.

(60) Bourgeois, M.; Guerard, F.; Alliot, C.; Mougin-Degraef, M.; Rajerison, H.; Remaud-Le Saëc, P.; Davodeau, F.; Chérel, M.; Gestin, J.-F.; Barbet, J.; Faivre-Chauvet, A. Feasibility of the Radioastatination of a Monoclonal Antibody with Astatine-211 Purified by Wet Extraction. J. Label. Compd. Radiopharm. 2008, 51, 379-383. https://doi.org/10.1002/jlcr.1543.

(61) Pozzi, O. R.; Zalutsky, M. R. Radiopharmaceutical Chemistry of Targeted Radiotherapeutics, Part 3: Alpha-Particle-Induced Radiolytic Effects on the Chemical Behavior of ${ }^{211}$ At. J. Nucl. Med. 2007, 48, 1190-1196. https://doi.org/10.2967/jnumed.106.038505.

(62) Vaidyanathan, G.; Affleck, D. J.; Alston, K. L.; Zhao, X.-G.; Hens, M.; Hunter, D. H.; Babich, J.; Zalutsky, M. R. A Kit Method for the High Level Synthesis of [ ${ }^{211}$ At]MABG. Bioorg. Med. Chem. 2007, 15, 3430-3436. https://doi.org/10.1016/j.bmc.2007.03.016.

(63) Rajerison, H.; Faye, D.; Roumesy, A.; Louaisil, N.; Boeda, F.; Faivre-Chauvet, A.; Gestin, J.-F.; Legoupy, S. Ionic Liquid Supported Organotin Reagents to Prepare Molecular Imaging and Therapy Agents. Org. Biomol. Chem. 2016, 14, 2121-2126. https://doi.org/10.1039/C5OB02459E.

(64) Guérard, F.; Lee, Y.-S.; Baidoo, K.; Gestin, J.-F.; Brechbiel, M. W. Unexpected Behavior of the Heaviest Halogen Astatine in the Nucleophilic Substitution of Aryliodonium Salts. Chem. Eur. J. 2016, 22, 12332-12339. https://doi.org/10.1002/chem.201600922.

(65) Guérard, F.; Navarro, L.; Lee, Y.-S.; Roumesy, A.; Alliot, C.; Chérel, M.; Brechbiel, M. W.; Gestin, J.-F. Bifunctional Aryliodonium Salts for Highly Efficient Radioiodination and Astatination of Antibodies. Bioorg. Med. Chem. 2017, 25, 5975-5980. https://doi.org/10.1016/j.bmc.2017.09.022.

(66) Gouard, S.; Maurel, C.; Marionneau-Lambot, S.; Dansette, D.; Bailly, C.; Guérard, F.; Chouin, N.; Haddad, F.; Alliot, C.; Gaschet, J.; Eychenne, R.; Kraeber-Bodéré, F.; Chérel, M. Targeted-Alpha-Therapy Combining Astatine-211 and Anti-CD138 Antibody in a Preclinical Syngeneic Mouse Model of Multiple Myeloma Minimal Residual Disease. Cancers 2020, 12, 2721. https://doi.org/10.3390/cancers12092721.

(67) Navarro, L.; Berdal, M.; Chérel, M.; Pecorari, F.; Gestin, J.-F.; Guérard, F. Prosthetic Groups for Radioiodination and Astatination of Peptides and Proteins: A Comparative Study of Five Potential Bioorthogonal Labeling Strategies. Bioorg. Med. Chem. 2019, 27, 167-174. https://doi.org/10.1016/j.bmc.2018.11.034. 
(68) Aneheim, E.; Gustafsson, A.; Albertsson, P.; Bäck, T.; Jensen, H.; Palm, S.; Svedhem, S.; Lindegren, S. Synthesis and Evaluation of Astatinated N-[2-(Maleimido)Ethyl]-3(Trimethylstannyl)Benzamide Immunoconjugates. Bioconjugate Chem. 2016, 27, 688697. https://doi.org/10.1021/acs.bioconjchem.5b00664.

(69) Reilly, S. W.; Makvandi, M.; Xu, K.; Mach, R. H. Rapid Cu-Catalyzed [ ${ }^{211}$ At]Astatination and $\left[{ }^{125} \mathrm{I}\right]$ Iodination of Boronic Esters at Room Temperature. Org. Lett. 2018, 20, $1752-$ 1755. https://doi.org/10.1021/acs.orglett.8b00232.

(70) Jadvar, H.; Chen, X.; Cai, W.; Mahmood, U. Radiotheranostics in Cancer Diagnosis and Management. Radiology 2018, 286, 388-400. https://doi.org/10.1148/radiol.2017170346.

(71) Amaouch, M.; Montavon, G.; Galland, N.; Pilmé, J. What Can Tell the Quantum Chemical Topology on Carbon-Astatine Bonds? Mol. Phys. 2016, 114, 1326-1333. https://doi.org/10.1080/00268976.2015.1120361.

(72) Wilbur, D. S. $\left[{ }^{211}\right.$ At]Astatine-Labeled Compound Stability: Issues with Released $\left[{ }^{211} \mathrm{At}\right]$ Astatide and Development of Labeling Reagents to Increase Stability. Current Radiopharm. 2008, 1, 144-176.

(73) Teze, D.; Sergentu, D.-C.; Kalichuk, V.; Barbet, J.; Deniaud, D.; Galland, N.; Maurice, R.; Montavon, G. Targeted Radionuclide Therapy with Astatine-211: Oxidative Dehalogenation of Astatobenzoate Conjugates. Sci. Rep. 2017, 7, 2579. https://doi.org/10.1038/s41598-017-02614-2.

(74) Ludwig, R.; Fischer, S.; Dreyer, R.; Jacobi, R.; Beger, J. Complex Formation Equilibria between Astatine(I) and Sulphur-Containing Chelating Ligands. Polyhedron 1991, 10, 1117. https://doi.org/10.1016/S0277-5387(00)83540-8.

(75) Ning, L.; Jiannan, J.; Shangwu, M.; Hengliu, C.; Yanping, Y. Preparation and Premilinary Evaluation of Astatine-211 Labeled IgG via DTPA Anhydride. J. Rad. Nucl. Chem. 1998, 227, 187-190. https://doi.org/10.1007/BF02386459.

(76) Ayed, T.; Pilmé, J.; Tézé, D.; Bassal, F.; Barbet, J.; Chérel, M.; Champion, J.; Maurice, R.; Montavon, G.; Galland, N. ${ }^{211}$ At-Labeled Agents for Alpha-Immunotherapy: On the in Vivo Stability of Astatine-Agent Bonds. Eur. J. Med. Chem. 2016, 116, 156-164. https://doi.org/10.1016/j.ejmech.2016.03.082.

(77) Fujiki, K.; Kanayama, Y.; Yano, S.; Sato, N.; Yokokita, T.; Ahmadi, P.; Watanabe, Y.; Haba, H.; Tanaka, K. ${ }^{211}$ At-Labeled Immunoconjugate via a One-Pot Three-Component Double Click Strategy: Practical Access to $\alpha$-Emission Cancer Radiotherapeutics. Chem. Sci. 2019, 10, 1936-1944. https://doi.org/10.1039/C8SC04747B.

(78) Wilbur, D. S.; Chyan, M.-K.; Hamlin, D. K.; Vessella, R. L.; Wedge, T. J.; Hawthorne, M. F. Reagents for Astatination of Biomolecules. 2. Conjugation of Anionic Boron Cage Pendant Groups to a Protein Provides a Method for Direct Labeling That Is Stable to in Vivo Deastatination. Bioconjugate Chem. 2007, 18, 1226-1240. https://doi.org/10.1021/bc060345s.

(79) Pruszyński, M.; Łyczko, M.; Bilewicz, A.; Zalutsky, M. R. Stability and in Vivo Behavior of Rh[16aneS4-Diol] ${ }^{211}$ At Complex: A Potential Precursor for Astatine Radiopharmaceuticals. Nucl. Med. Biol. 2015, 42, 439-445. https://doi.org/10.1016/j.nucmedbio.2014.12.011.

(80) Rajerison, H.; Guérard, F.; Mougin-Degraef, M.; Bourgeois, M.; Da Silva, I.; Chérel, M.; Barbet, J.; Faivre-Chauvet, A.; Gestin, J.-F. Radioiodinated and Astatinated NHC Rhodium Complexes: Synthesis. Nucl. Med. Biol. 2014, 41, e23-e29. https://doi.org/10.1016/j.nucmedbio.2013.12.004. 
(81) Vernon, R. E. Which Elements Are Metalloids? J. Chem. Educ. 2013, 90, 1703-1707. https://doi.org/10.1021/ed3008457. 